This document is downloaded from DR-NTU (https://dr.ntu.edu.sg) Nanyang Technological University, Singapore.

Misinformation in fashion product labels : an

examination of strategic cues that compel

consumption

Chan, Edward Ching Mun

2018

http://hdl.handle.net/10356/73250

https://doi.org/10.32657/10356/73250

Nanyang Technological University

Downloaded on 26 Apr 2023 17:51:30 SGT 

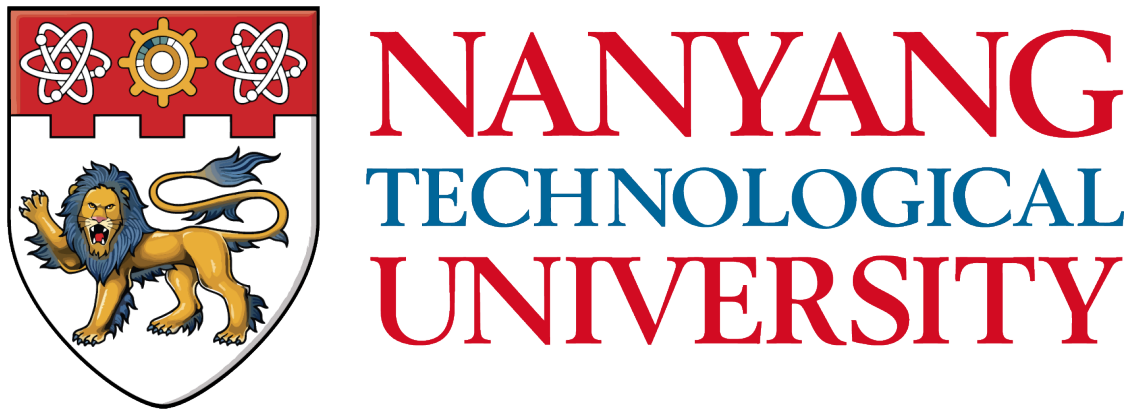

MISINFORMATION IN

FASHION PRODUCT LABELS:

AN EXAMINATION OF STRATEGIC CUES

THAT COMPEL CONSUMPTION

CHAN CHING MUN EDWARD

WEE KIM WEE

SCHOOL OF COMMUNICATION AND INFORMATION 2018 


\section{MISINFORMATION IN \\ FASHION PRODUCT LABELS: \\ AN EXAMINATION OF STRATEGIC CUES \\ THAT COMPEL CONSUMPTION}

CHAN CHING MUN EDWARD

Wee Kim Wee School of

Communication and Information

A thesis submitted to the Nanyang Technological University

in partial fulfillment of the requirement for the degree of

Master of Mass Communication 


\begin{abstract}
This research attempts to accord focus toward the investigation of misinformation in fashion product labelling. Because of growing socio-ecological awareness of global conditions in manufacturing; country-effects, green and fair trade claims on products seem to be rising in demand. With the evolution of this phenomenon, the manipulation of information on product labels becomes a critical tool that is being used to drive consumption. This research investigates the strategic information cues on the product label. As a largely unregulated aspect of the retail business, the accuracy of information on fashion product labels seem to have come under scrutiny, after numerous recent high-profile mislabelling cases that have emerged. These product information claims seem to serve the purpose of marketing and promoting consumption, as opposed to the original service of accurate consumer knowledge. Content analysis of existing fashion product labels from popular brands in the market will be the key methodology employed in the assessment of these information tools. A sample size of 60 products, from the Robinsons department store and other high-profile brands in the region, were selected for this analysis. In this research, country-effects such as the country of origin (COO) label has been identified as one of the key tools used as communication strategy in compelling consumption. However, upon further analysis, out of the 51 product tags with a COO labelled, only 8 were labelled with a COO on the high desirability scale and 36 were labelled with a COO on the low desirability scale. Further, other parallel country-effects like the country of design (COD) and country of establishment (COE) labels did not make up for the low frequency of COO being used as a tool in strategic product labelling. These results suggest that a further study is required in order to understand the evolution of other limiting factors that could be driving consumption.

Product labelling; information cues; fashion markets; country-effects; green and fair trade; consumption
\end{abstract}




\section{Acknowledgements}

I would like to gratefully acknowledge Professor May O. Lwin and Ms. Chitra Panchapakesan in their advice towards the completion of this dissertation. 
Table of Contents

1.1 Introduction and Statement of Problem 6

2.1 Background and Case Studies 8

2.1.1 Labels and consumer education

2.1.2 Industry response to consumers' growing desires for green and ethical products

2.1.3 Case studies on high-profile mislabelling of fashion products

2.2 Literature Review 14

\subsubsection{Ethical Purchasing Gap}

2.2.2 Difficulty in the assessment of benefits of green labelling

2.2.3 Country effects in product labelling

2.2.4 Evolution of the COO strategy: from country image to a community story

2.2.5 Consumers' prior knowledge and transparency of product content increases confidence in consumption

2.2.6 Evolution from literal to visual cues in product labelling

2.2.7 Labelling standards in the industry

2.2.8 Implications of a mandatory $\mathrm{COO}$ label

3.1 Research Questions 41

4.1 Methodology 42

4.1.1 Sample

4.1.2 Variable measurement

4.1.3 Justification of country desirability scales [COO]

4.1.4 Justification of the green scale

5.1 Findings 48

6.1 Discussion 54

6.1.1 Primary findings from the data

6.1.1 Vision for the future: transparent and truthful labelling?

6.1.2 Health and food labelling practices as potential reference model

7.1 Limitations 61

8.1 Conclusion 61 


\section{$\underline{1.1 \text { Introduction and Statement of Problem }}$}

This research will focus on the problem of misinformation in the product labelling practice within fashion, its relevant strategies and why it is critical in study. The objective is to increase understanding of the different cues that brands frequently use as strategic tools to manipulate consumers and drive consumption and commerce. We aim to define the commercial motivations and assess product labelling cues (or miscues) used to achieve commercial ambitions of fashion businesses.

Green retail represents a recent key strategy adopted by brands in product labelling. There has been a growth of cases in the misinformation of fashion product labels, as retailers are starting to "jump onto the bandwagon of green retailing" (Lee et. al., 2012). As consumer awareness of the world's natural environments increases, customers have shown a parallel interest with an increase in global demand for green products. Major global retail players have thus created product tags that claim environmental benefits, or green labels: examples of cases include the Green Collections of Gap and Carbon-Neutral Lingerie of Marks \& Spencer. Ecological indices were also initiated in order to aid customers in the evaluation of 'greenness' of suppliers and/or products for practising sustainability (e.g., Sustainability Index of Wal-Mart and the Eco IndexTM of The U.S. Outdoor Industry Association) (Lee et. $a l$.). Because of this growing international demand for ethical products, the problem of misinformation becomes amplified.

Fair trade labelling assumes another critical area related to this issue, as it was established to overcome the undesirable consequences of free trade strategies in manufacturing, which aided the transnational growth of corporations and the sourcing of global production with the lowest labour costs (Jones and Williams, 2012). Because of this phenomenon, many manufacturing communities, especially in developing countries, 
experience the fate of having to succumb to transnational power by absorbing the sociological, monetary and ecological costs at multiple levels of the supply chain.

The commercial motivations to create a falsehood of this nature are many, and its relevant motivations involve diverse fields of study. For example, critical aspects of misinformation in labelling include country references for production (COO) and brand establishment origins (COE), fibre content and garment sizes.

The extravagant nature of fashion further enhances the need to be critically aware: As an industry that is largely impacted by trends and highly reliant on the relentless need for existing designs to be replaced in order to stay popular, it is reasonable to be directed at for consumerism and waste (Han and Chung, 2014). The ecological impact of the fashion industry has become increasingly destructive because of the relentlessness in consumer demand for a hastened circle of the fashion system (O'Cass, 2004) and demands for everdecreasing garment prices (Morgan and Birtwistle, 2009), and further encouraged by lower production costs in developing manufacturing communities (Jones et al., 2005 cited in Ritch and Schröder, 2012). The consumerism culture of fashion and competitive production costs have led to the inevitable exploitation of resources in developing countries, resulting in loss of wealth, transgenerational genetic effects, and massive loss of lives in the most extreme of instances. It is hence important that labels of sustainability and fair trade are championed not as mere marketing strategy in products, but by manufacturing standards bound in policy and regulation, and the accurate communication of those standards.

Hence this study will attempt to identify the common marketing strategies executed by fashion businesses in their product labelling practices. The objectives of this research are (a) to identify the most commonly, prominently and visibly labelled information type, as well as their relative relationships with the other information that are also present on the label; (b) the significance of country labels labelled in terms of brand origins, design origins and 
production origins, as well as their relationship with one another in relative desirability; and (c) the parallel communication of both verbal and visual green concepts on the product label.

\subsection{Background and Case Studies}

\subsubsection{Labels and consumer education}

There are two main categories of product labelling related to ethical production in the fashion market. Fair trade and green labels are producer-centric and are largely associated with ethical processes either down the value chain or post-supply-chain at the disposal stage, while health and food safety labels are consumer-centric and are involved with the consumption stage upwards of the same value chain. (Melser and Robertson, 2005).

There are several aspects that make green labels different and more controversial than their health and safety counterparts. First, while health and safety issues are generally consistent across national regulations, attitudes toward the environment could be vastly disparate (Melser and Robertson, 2005). This allows for disagreement across country regimes over the validity of an environmental issue. Also, because of the income-elastic nature of demand over ecological ethics, the disparity of philosophies and attitudes are largest between economically most developed and the least developed countries. Hence, there is industry concern regarding motives for eco-labelling practices by developing-country exporters. This issue is increasingly surfaced when it involves mandatory eco-labelling policies (Melser and Robertson, 2005, pp. 50-51), where there is a running risk of developing exporters labelling goods only for the purpose of overcoming trade barriers.

Secondly, since green labels contain information regarding potential environmental impacts, they are designed to inform consumers about ecological costs that were incurred at the manufacturing stage and at the would-be disposal end of a product's life cycle (Melser and Robertson, 2005). Health and safety labels on the other hand, are concerned with costs 
that occur during the consumption stage. Thirdly, there is a critical difference in labelling motivations. The effectiveness of health and safety labelling in communication depends on a consumer's willingness to pay the premium to preserve their own personal welfare. Green labelling, however, depends on the consumers' willingness to preserve their external environment. Thus, eco-labelling is highly dependent on the consumers' desires to contribute to the welfare of the larger community (Melser and Robertson, 2005). The motives facing the consumers are evidently very different.

Green labelling was promoted as one of the key solutions to resolve the impacts of globalisation and its effects on resource deregulation. Unfortunately, high certification standards can often victimise the intended "beneficiaries" of the certification, be it the environment, the producers, or both, to the demands of consumers and the wider markets (Getz and Shreck, 2006 cited in Hadjimichael and Hegland, 2015). As described, the disparity of attitudes of production-related issues across national regimes and individual consumers at both the global and personal levels respectively, are intense. Therefore, it is reasonable to agree that producer-centric labels that encourage ethical behaviours in consumption are more challenging in regulation and control, especially since its motivations are extrinsic to the consumer.

\subsubsection{Industry response to consumers' growing desires for green and ethical products}

Because of the world-wide dwindling of ecological resources (Tang, Fryxell and Chow, 2004), regulatory bodies have been strategising tools to propel commerce and society towards more balanced practices that are more sustainable. Examples of such approaches included the use of socioeconomic devices such as taxes, rebate programmes, education campaigns, curriculum development, etc. (Tang et al., 2004).

One promising communicative strategy that complements the workings of market forces is the use of green labels on products. With acknowledgement that consumers respond 
positively to environmental claims (e.g., Chase and Smith, 1992; Hayhurst, 2000; Salzman, 1991; Wiltberger, 1999 cited in Tang et al., 2004), green labels serve as a credible and effective communication tool to represent the environmental-friendliness of a particular product (Hansen and Kull, 1994; Scammon and Mayer, 1993 cited in Tang et al., 2004). An eco-label can refer to any iconography that is present on the product packaging, with the aim of informing customers that the said product is ecologically less harmful, compared to other alternatives (Tang et al., 2004).

A consumer survey in Singapore from 1991 revealed that almost all its respondents indicated that they would like to know where they could purchase merchandise that were environmentally friendly (Shamdasani et al., 1993 cited in Tang et al., 2004). Similarly, a study of more than 5000 residents in Hong Kong concluded that more than $50 \%$ of those surveyed claimed to have shopped for responsibly-manufactured goods which were environmentally-safe (ECCO, 1996 cited in Tang et al., 2004). Therefore, it is clear that there has been a growing consumer demand for green products, in economically more-developed Asian societies.

The pioneer "seal of approval" programmes such as the "Blue Angel" was initiated in Germany in 1977. It incorporated both visual and verbal cues to communicate to consumers the environmental attributes of the product. "The visual cue consisted of a blue female figure surrounded by a blue ring with a laurel wreath. The verbal cue consisted of an inscription reading 'Environmental label, because . . 's specifying the primary virtue of the certified product or service (e.g., recyclability, energy efficiency or an absence of toxic materials)" (Tang et al., 2004, pp.87). In contrast, subsequent versions of eco-labels developed in other markets have generally been designed to communicate an ecological symbol with general literal descriptions to ascertain its green-label nature, without making reference to the product's environmental background (Tang et al., 2004). Evidently, the evolution of the 
green label from its original "seal of approval" purpose, proved to be a growing commercial problem that could have serious socio-ecological implications.

\subsubsection{Case studies on high-profile mislabelling of fashion products}

A recent high-profile case in the United States (US) involved the fining of 4 major retailers: Bed Bath \& Beyond, Nordstrom, JCPenny and Backcountry.com for noncompliance of the Federal Trade Commission (FTC) Act and its textile regulations (FTC, 2015). The FTC made the public statement of the complaints that disapproved the four retailers from the mislabelling practice and willful advertising of rayon textiles as bamboo fibres, requiring them to pay civil penalties of US\$1.3 million (FTC).

The FTC added that these cases were examples of disinclination on the part of retailers to make the correction despite initial warnings, due to the bamboo fibre's commercial appeal in the market. The 2015 statement announced alleged that the companies were in violation of the law by the misrepresentation of rayon products as bamboo, regardless of warning letters in 2010. The Commission charged the companies with violating Section $5(\mathrm{~m})(1)(\mathrm{B})$ of the FTC Act by deceptively advertising the mislabelled products, despite knowledge of illegality (FTC). This case study demonstrated the overwhelming strategy of the brands to ensure consumption and commerce, by manipulating specific cues in the product label.

Another case involved a US denim and jeans manufacturing company, on the mislabelling practice of the information on the country of origin. Lawsuits were filed against Citizens of Humanity and AG Adriano Goldschmied asserting that their American-made product labels were erroneous because they were substantially manufactured from component parts that were produced and sourced from outside of the US, which was in violation of the California and federal law at the time (Belgum, 2014). It also went on to reveal profitoriented motivations from the fraudulently concealed information (Belgum, 2014). 
Again, due to the complexity of the fashion system and its global supply chain (Ritch and Schröder, 2012), this particular case revealed the businesses' deception of their customers. Court documents indicate that many consumers have very limited information on the likelihood that merchandise and their composite parts, claimed to be made in the United States are in fact made in foreign countries. Consumers need to understand that many labels reveal certain information that could be inaccurate. Many retailers simply do not follow guidelines as closely as they should. With reference to Californian law, in order to justify a "Made in USA" label, all of the components have to be US-sourced, indicated Donboli, the attorney who filed the case. However, if the product is an imported good, such as fabric, and has already been substantially altered in the US, the product does not need to be marked with the actual country of origin (Belgum, 2014).

While the substantial transformation of an imported product in the US may exempt a manufacturer from a country-of-origin labelling, the product does not automatically qualify for the "Made in USA" tag. This substantial alteration represents the initial hurdle faced by manufacturers that wish to place a domestic-origin marking on their product. Significant components and processing that go into the production of the merchandise must be USsourced in order to qualify for the coveted US-made label (Belgum). Because of the customers' desirability of American goods in their local markets, the "Made in USA" tag has clear commercial benefits to businesses.

The next case illustrates the hypocrisy of a marketing campaign of the international English heritage brand Burberry that involved deliberate misinformation in product labelling. The Burberry marketing campaign has a global reach and revolves around communicating the message of a luxury brand with a clear British appeal, that allowed the business to profit approximately US\$475m per year, while cutting UK jobs with the closure of local factories (Cadwalladr, 2012). This is an industry example of a cover-up strategy of allocating the 
manufacturing arm of Burberry from the UK to China, while still retaining the "Made in England" label (See Exhibit 1).

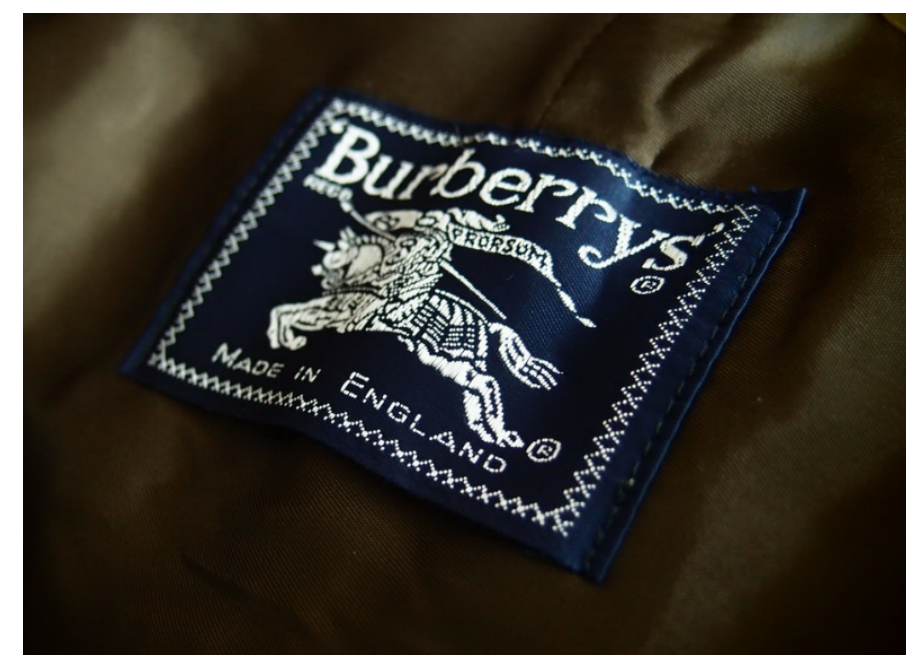

Exhibit 1: Burberry and its "Made in England" label.

According to Cartwright in an interview in 2007, moving jobs to China was inevitable. However, she also indicated the justness of the decision, attributing to higher British labour costs (Cadwalladr, 2012). Therefore, because of the fact that much of Burberry's production no longer remained in the UK, the "Made in England" label (Exhibit 1) becomes deliberately deceptive. Further, the fact that Burberry is a high-profile luxury brand, amplifies the problem. According to Cadwalladr (2012), luxury brands represent the most strategic moves in boosting customer confidence when making purchase decisions; retail prices of merchandise in the market have a detached relationship with manufacturing costs. In the market today, consumers are more relatable to attributes such as exclusivity, quality and trendiness of the product. According to Cadwalladr (2012), these were mirrored in Burberry's case as inauthenticity, hypocrisy and greed.

The rise of these manipulation of information cues serves the primary purpose of driving higher price premiums and consumption levels. Therefore, the increase in frequency of cases in the mislabelling of fashion products warrants consumer market awareness, industry scrutiny and renewed regulation. 


\section{$\underline{\text { 2.2 Literature Review }}$}

\subsubsection{Ethical Purchasing Gap}

According to Berry and McEachern, (2005 cited in Bray et al., 2010, pp.597), there has been growth in responsible consumption. A longitudinal research study by the Cooperative Bank reported that sales of responsibly-made goods increased between 2004 and 2007 at approximately 12\% annually, and landed at approximately US\$45 billion in 2007 (Clavin, 2008 cited in Bray et al., 2010). Contradictorily, while growth patterns indicate potential, revenue in this area still represent less than $6 \%$ of the total consumer market worth US\$780 billion (Macalister, 2007 cited in Bray et al., 2010).

A Cowe and Williams' study in 2000 discovered that more than $33 \%$ of consumers in the UK labelled themselves as "ethical purchasers", however responsibly-manufactured merchandise, such as product ranges with fair trade origins, merely accounted for $1-3 \%$ share of the market. Cowe and Williams coined this observation the "30:3 phenomenon". This theory seeks to explain that of the $30 \%$ of consumers who identify being concerned about ethical standards, only $3 \%$ of purchases is observed in the market. This social phenomenon has been independently noted by other academics and has also been coined as the "Ethical Purchasing Gap" (Nicholls and Lee, 2006 cited in Bray et al., 2010, pp.597) and the "Attitude Behaviour Gap” (Kim et al., 1997 cited in Bray et al., 2010, pp.597). 


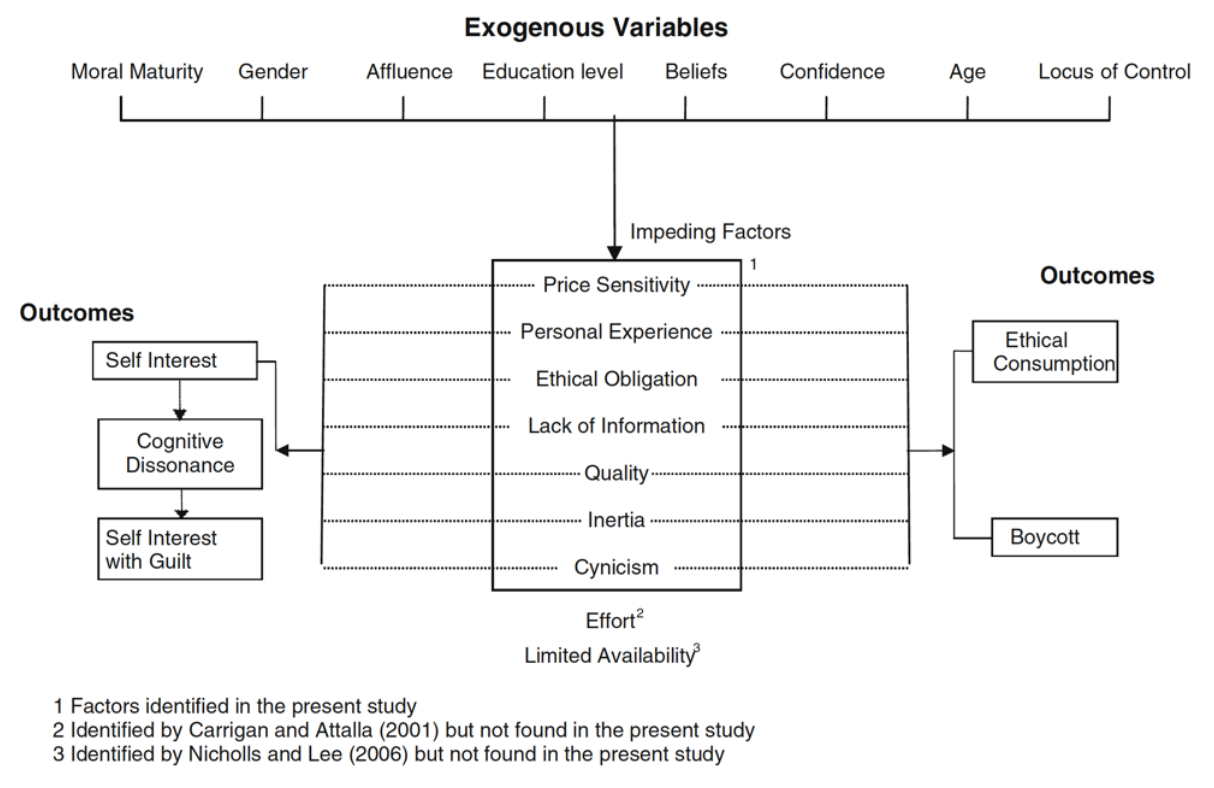

Exhibit 2: Factors impeding ethical consumption.

With reference to Exhibit 2 in Bray et al. (2010), there are several contributions of factors towards the understanding of the Ethical Purchasing Gap: "Price sensitivity, personal experience, ethical obligation, lack of information, quality perception, inertia in purchasing behaviour, cynicism and guilt" (Bray et al., 2010, pp.601-603). Therefore, the factors that affect purchase of ethical goods are many. The "lack of information" as a potential limiting factor towards customers' product purchase illustrates the importance of brands in providing accurate, thorough product information that aids informed buying decisions. However, this could potentially reflect the strategy of brands in over-communication of information on their product labels, seemingly providing transparency. On the other hand, as this research paper would outline, product retail prices remain a central concern around which all business strategies and consumer buying decisions would revolve.

The undesirable results in consumer buying behavior hence do not appear to provide a satisfactory explanation for the continued emergence and spreading of eco-labelling schemes. Rather, their infiltration in the markets seems like a result from retail marketing and their commitment to "sustainability", aiding the eco-labelling concepts to gain more accessibility 
and demand in the markets (Gulbrandsen, 2006 cited in Hadjimichael and Hegland, 2015). Evidently, green labels no longer promise consumers in their contribution to a more sustainable world, but rather serve a mere commercial motivation.

\subsubsection{Difficulty in the assessment of benefits of green labelling}

The critical research value of this product label misinformation phenomenon is also questioned, if green labels are by nature, ineffective to its original purpose. Comparatively, the benefits of accurate health and safety labelling are clear, due to direct implications on the consumer. From consumer perspectives, there remains a challenge in warranting the importance of purchasing commercial products, especially with limited evidence of its desired merits from this process (Melser and Robertson, 2005, pp. 53).

From the perspective of the customer, it is argued that even if there is a thorough labelling system in place, the consumer's motivations to prioritise benefits directly related to $\mathrm{him} /$ herself will remain stronger at the expense of potential benefits to the manufacturers and their working and living environments down the value chain. Although there are theoretical effects of green labels in creating markets for green products, the concern of whether the selfinterest motive provides sufficient motivations for consumers to act, in order to alleviate costs on our environments (Melser and Robertson, 2005, pp. 55). Another study also concluded that some customers would still make their purchase decisions despite informed product labelling: "It is debatable whether the majority of consumers would truly forgo their selfinterest in order to purchase alternatives produced under ethically acceptable conditions" (Joergens, 2006, pp. 360). Insufficient number of market studies have been executed for the investigation into the consumers' view on ethical issues in the fashion markets and their subsequent impacts on buying behaviours (Dickson, 1999, 2000; Balzer, 2000, cited in Joergens, 2006). There is no strong enough indication that accurate labelling actions lead to the intended social and environmental effects. 
However, the effects from an accurate and informative product labelling system cannot be pessimistic, even though effects are under-studied. Although there are grounds to reject eco-labels due to their apparent disability in solving environmental problems, it is of value to account green labelling information only as a composite of the objective of the entire labelling programme. Also, since there are external costs associated with the consumption decisions, even a faultless labelling programme would not compel customers to internalise these costs. To a large extent, benefits of green labelling should hence be assessed as a component of policies for environmental regulation (Melser and Robertson, 2005). It needs to be emphasised that a regulated labelling decorum for the ethical consumption of goods should be seen as a part of a more comprehensive policy for international trade.

Based on a study by Joergens (2006), a focus group discussion revealed that although respondents were aware of the ethical issues that were prevalent in the garment industry and were aware of the working conditions in manufacturing communities of developing countries, this knowledge did not pose an issue during shopping (Joergens, 2006). While this is a meritable justification that evidences the lack of intended benefits from ethical product labelling, the fashion industry cannot discount the need for a transparent and accountable labelling system, at the expense of the conscientious customer's right to product knowledge.

Again, from the industry standpoint, we have to question if the seeming absence of stringent regulations for green product labelling have paralysed the original merits of the product labeling system. We question if the function of green labelling has become diluted to a purpose that purely serves commercial ambitions.

\subsubsection{Country effects in product labelling}

Most researchers identify the country of origin (COO) as a product label cue; some of them treat the $\mathrm{COO}$ as an external product attribute in product evaluation (Bilkey \& Nes, 1982; Hong \& Wyer, 1989; Maheswaran, 1994; Okechuku \& Onyemah, 1999; Supanvanij \& 
Amine, 2000 cited in Rashid, 2016). Erickson, Johansson, and Chao (1984 cited in Rashid, 2016) interpret COO as an image variable. Many researchers have investigated consumers' product evaluations for products made in favorable and unfavourable countries. Many suggest a halo effect or bias for favourable or unfavourable COOs (Wilcox, 2015 cited in Rashid, 2016). The COO as an information tool is evidently a critical strategy utilised by businesses to manipulate consumption. Depending on the desirability or favourability of the country in question, the COO label accentuates the strength of the origin country (Merk, 2011; Papadopoulos \& Heslop, 1992; Quelch, 1999 cited in Rashid, 2016).

Maheswaran (1994 cited in Rashid, 2016) suggests that COO works as a stereotyping process that can affect product evaluation in three ways: (a) $\mathrm{COO}$ as a customer's signal; consumers generalise their pre-conceived notions of product quality made from a specific country to superimpose the quality of all other merchandise from various products categories from that same country of origin (Hong \& Wyer, 1989 cited in Rashid, 2016); (b) COO is an external product attribute that is used in product evaluation against other product attributes (Li \& Monroe, 1992 cited in Rashid, 2016); (c) COO can work as knowledge that is universally-applicable in order to simplify their product evaluation process for all situations that involve making purchase decisions (Hong \& Wyer, 1989 cited in Rashid, 2016). This enables the generalisation of the quality of a product manufactured by a particular country, thereby creating a brand image associated with certain countries; making some countries more desirable as COOs on the product label.

However, many studies have found that brand equity and brand origin are far stronger cues that can override the negative COO effect (Cordell, 1991; Cordell, 1993, Erickson et al., 1984; Eroglu \& Machleit, 1989 cited in Rashid, 2016). Brand origin or the country of establishment of a brand, hence, could have a greater impact compared to the COO image. Therefore, there is also value in the investigation of the comparable desirability of a brand's 
establishment origin and its products' production origin (COO), and the negative downstream consequence of the discrepancy of favourable ratings of these two origins.

Apart from country classes, product specialty from a certain brand, or merchandise belonging to a particular product category could also contribute to factors involving buying decisions. In recent years, accusations of sweatshop practices against specialty garment and footwear brands over the last twenty years could have increased consumer knowledge of human rights concerns. Future studies can investigate whether consumers attribute their concerns to a certain product category or to the specific brand of the product categories (Passariello, 2013 cited in Rashid, 2016). Therefore, future research can investigate the variability of negative downstream consequences of sweatshop exploitation on the various brand classes (luxury versus non-luxury) and product categories (symbolic versus functional). Expectedly, a negative brand image, or a negative product type, might have unfavourable associations, equivalent to having an undesirable COO.

In fashion, product sales are still largely driven by popular brands, fads and trends, instead of any deeper meaning in purchasing behaviours. According to a Joergens (2006) study, the results inferred that the consumer interest in a fashion business's ethical conduct seems to be limited. Despite negative light in global news coverage on brand names, UK participants continued purchasing merchandise from Nike and Gap, simply because they liked them. Although most subjects stated that they have negative perceptions towards the apparel industry, this knowledge or awareness is not a factor of consideration when they are shopping (Joergens, 2006). This demonstrates the durability of the established brand image, despite negative light associated with business practice.

However, other studies have shown that a country's particular image influences purchase decisions significantly, even more so compared to a brand name (Papadopoulos and Heslop, 2000). This is especially applicable for brands without the high-profile reputations; 
the $\mathrm{COO}$ is a strategic tool used to enhance product image. For instance, a German or Japanese COO can enhance brand equity greatly. Country images are perceived to be convenient for consumers because they are more readily accessible references, and can be used to make inferences of the qualities of the product. For sellers, the $\mathrm{COO}$ tag also becomes a key strategy that is used to differentiate their offerings, in the face of an internationally homogenous market (Papadopoulos and Heslop, 2000).

In Papadopoulos and Heslop's (2000, pp.32) study, when evaluating countries, buyers use the following criteria: “(1) a country’s level of advancement; (2) their own feelings about its People; and (3) their desire for closer links with the country in question." Therefore, the value of the country effect cannot be underestimated.

As Luca Solca (2015), the head of luxury goods at BNP Exane Pariba, details how consumers are concerned about the origin of the goods that they purchase. For example, as the largest nation of luxury consumers in the world, the Chinese desire their watches to be Swiss-made, France as the preferred origin for their perfumes and cosmetics, their cars to be German-made and their bags and footwear products to originate from Italy or France. Evidently, it is corroborated here that consumers have expectations of ideal country labels based on the product category. However, many luxury brands are reluctant about the disclosure of the country of origin of their products. There is a general recognition of the benefits of the full disclosure of the COO. This is especially true for some brands that boast of a manufacturing heritage, so that they could exploit it (Solca, 2015). Most of the luxury brands opt for partial disclosure, depending on several key limiting factors such as market positioning and the extent of their history and establishment.

A joint study of the strategy of COO disclosures by Contact Lab and Exane BNP Paribas of major luxury brands found that brands fall into four broad groups: The first group included brands that presented full disclosure of $\mathrm{COO}$ on their web product pages and were 
transparent regarding production in heritage countries on most of their merchandise. This group involved the study of luxury brands such as Bottega Veneta, Brunello Cucinelli, Valentino, Saint Laurent, Gucci, Balenciaga, Fendi and Tod's. The second group comprised of companies with $\mathrm{COO}$ disclosures on web merchandise pages but only declared production in heritage countries and involved only "high-level product lines... For example, Burberry declares "Made in the UK" and "Made in Italy" for Burberry Prorsum, while tagging its lower cost British line with "Imported"; Armani declares "Made in Italy" for Giorgio Armani and "Imported" for Armani Jeans; Ralph Lauren declares "Made in Italy" for Ralph Lauren Collection and "Imported" for Polo Ralph Lauren" (Solca, 2015, pp.1). It is apparent that when the disclosure of the $\mathrm{COO}$ involved a non-desirable country reference, luxury brands will re-strategise relevant signposting in their other product cues.

The third group of companies were generally not transparent on their web product pages, even though they declared minimal production in heritage countries. In the study, Hermès, Loro Piana, Louis Vuitton, Ermenegildo Zegna and Salvatore Ferragamo were grouped into this category. Finally, there were brands with minimal or no COO disclosures on their product pages and made no reference to production in heritage manufacturing communities. These included brands such as Chanel, Dior, Prada, Dolce \& Gabbana, Hugo Boss, Coach and Tory Burch (Solca, 2015).

Brands with Italian origins have a clear advantage, as most of their manufacturing of highly-priced, high-end goods are based in Italy. For these brands, the "Made in Italy" COO label is a consistent winning marketing message that "reinforces their brand positioning." The prestige associated with the Italian COO declaration is hence clear, especially when it involves warranting a brand premium for the purchase of their products. However, some Italian luxury brands seem to have a non-COO disclosure strategy, de-emphasising the need for a "Made in Italy" endorsement. Loro Piana, Salvatore Ferragamo and Ermenegildo Zegna 
are examples included in the third group in the study. Historically, Prada championed the "Made by Prada" label for its merchandise, in order to de-emphasise COO qualifications. However, after significant manufacturing investments in the Tuscany region of Italy, the brand re-strategised the declaration of the COO label onto their products (Solca, 2015). Therefore, the COO label clearly exists to support commercial ambitions of companies and their shareholders.

Some mid-level luxury brands do not declare the COO of their products, because of their known undesirability to consumers. Otherwise, brands like Coach and Tory Burch would have to declare a "Made in China" tag or another similar low labour cost country as their COO. From the perspective of the Chinese and other customers from emerging markets, this transparency devalues desirability of the brand or its products. However, again, there are exceptions such as Michael Kors and Moncler, which are very transparent, that label nonheritage countries as their COO” (Solca, 2015).

Tom Adams (2015), the Global Head of Strategy at FutureBrand, confirms that consumers are increasingly more aware of the origin of their products. In a recent FutureBrand study, the COO was a more important determinant of purchase decisions compared to price or availability and is second only to safety. In other words, consumers prefer brands from particular countries or regions and prefer them to brands that lack a provenance story.

There is an increasingly popular business strategy that distinguishes a brand's design origins against its production origins (COO). This is evident in the case of Apple, where its products are designed in Cupertino, California, but are Chinese-made (Adams, 2015). Therefore, a product's design origins could serve to dilute the damaging effects of a COO with a negative image. This strategy however, would only be effective if the brand origin is from a country that is desirable for consumers. 
Many countries have perceived expertise in different product categories. For example, the US, France, Italy and the UK have provenance in fashion. The COO label is a driver of competitive advantage for brands, and it is no longer a function only limited to "manufacturing transparency and economic protectionism." (Adams, 2015, pp.1).

From a business strategy standpoint, the main aim of brands is to build equity and critical associations that would help maintain relevance to the target market and differentiated from competition. If $\mathrm{COO}$ is a critical tool in marketing on the product label because of a company's heritage, specialty or intellectual property, then it should be treated as a brand asset (Adams, 2015). Therefore, understandably, the COO is not always the most important tool for every brand.

\subsubsection{Evolution of the COO strategy: from country image to a community story}

COO labelling has proven to represent an increasingly important strategy for fashion brands. However, the community story from which the manufactured goods came, seems to be rising in importance in fashion goods. Safia Minney (2015), founder and chief executive of People Tree, argues that the fair trade factor is not only strategic, but more relevant towards the modern customer, as it attempts to make a personal connection to the customer (as illustrated in Exhibit 3), the maker of the product.

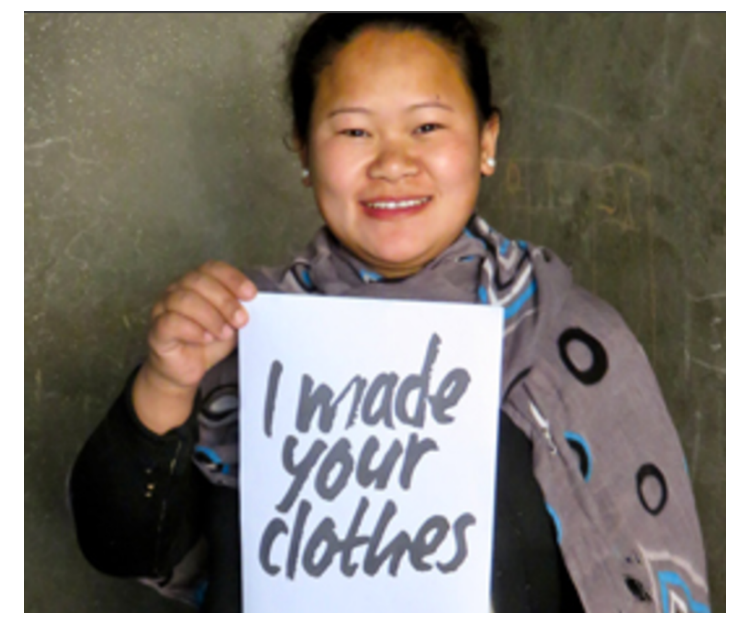

Exhibit 3: Fair trade as the next step from the COO: understanding the manufacturing community and its people. 
As indicated, because of the proliferation of country labels as a strategic marketing tool for signposting on commercial products, consumers have become accountable in making assessments based on the paralleled connotations from the COO label. The COO label hence represents the beginning of offering transparency and responsibility in consumption to the customer. Historically, this parallels previous consumer concerns, when consumers demanded for more favourable treatment for farmers of coffee and other agricultural goods in the early 1990s. This growth in concern has been brought on largely by the surfacing of subhuman working conditions in Bangladesh, from the collapse of the Rana Plaza factory complex. Despite repeated concerns from the factory workers, the accident, caused by the lack of funds for building maintenance killed 1,134 garment workers (Minney, 2015). This raised global awareness of the continuing abuse of human rights and environmental laws by fashion companies and their suppliers. The fashion industry needs to be more accountable towards the management of the supply chain transparency. As illustrated in this research, the labelling of the $\mathrm{COO}$ is critical, both for consumer information and business strategy. However, fair trade - the end users' knowledge of the community and livelihood of the makers of the products - seems to be rising in importance as the new strategy that stems from the COO labelling.

The World Fair Trade Organisation (WFTO cited in Minney, 2015) defines Fair Trade as a dialogue-based partnership in trade, in order to seek transparency and respect that could result in a greater equity in global free trade. Products manufactured through the fair trade channel can support sustainability in agriculture and preserve craft, while respecting the COO label and the direct community from which the makers originate. Nevertheless, while customers increasingly demand knowledge that the goods that they buy are made with respect for the people and their environment, consumers still consider fair trade purchases like regular ones, with considerations still highly based on aesthetic, brand, quality and value for 
money (Minney, 2015) - This is in accordance to many literature sources that were cited in this paper regarding the customers' priorities related to buying decisions. Parallel to the COO labelling strategy, fair trade respects that each country has a set of specific natural features due to the skills of its people, their heritage and their geographical location (Minney, 2015).

It is vital that the design processes involve heritage craft and skills in the production of its merchandise. Not only does this ensure that there is added value to the final product in the form of a unique selling point, socioeconomic advantages would also be brought to farming and artisan communities down the value chain (Minney 2015).

In view of the importance of third-party endorsements to consumers, the WFTO launched a new fair trade manufacturing labelling system in September 2013, which ensures that fair trade terms are fulfilled within the value chain, and assures consumers that corporations are championing the message (Minney, 2015). As a third-party product label, placing a WFTO tag on a product acts as a guarantee to the consumer that "manufacturers comply with the ten principles of fair trade: fair wages, working conditions, transparency, capacity building, environmental best practice, gender equality and setting standards for conventional fashion companies to improve their supply chains” (Minney, 2015, pp.1).

Another third-party certification employed by the People Tree brand is the Global Organic Textile Standard (GOTS) certified by the Soil Association. With 70 percent of their merchandise carrying the GOTS certification, developing-country farmers running small productions stand to receive a fair and stable price, and an additional premium giving them the opportunity to develop their communities. Just like other product labelling standards, third-party certifications also run the risk of acting as a barrier that works against the intended beneficiaries of that label. Certification needs to be accessible to the poorest farmers and makers in the developing counties. Therefore, fair trade represents beyond just detailing the 
$\mathrm{COO}$ of the product; it communicates the production story of the community, its heritage and its sustainability (Minney, 2015).

\subsubsection{Consumers' prior knowledge and transparency of product content increases confidence in consumption}

Prior knowledge of customers may influence how consumers process product information provided by fashion brands on their hang tags and product labels and what products they buy. D'Souza (2004 cited in Oh and Abraham, 2015) addresses the importance of accurate and understandable environmental labels as a marketing tool as it allows consumers to make an informed choice. Labels and hang tags for apparel products were found to provide consumers with useful information on decision making (Chowdhary, 2003 cited in Oh and Abraham, 2015).

The US law mandates that most textile-wearing products should have a label listing fibre content, country of origin, manufacturer details, and fabric care instructions (Bureau of Consumer Protection, cited in Oh and Abraham, 2015). In addition, most manufacturers of organic cotton clothing list additional information regarding manufacturing procedures, dye methods, shrinkage percentage, and the company's ethical accountability (Doane, 2002 cited in Oh and Abraham, 2015). The additional information may be useful to consumers of organic cotton clothing in assimilating customer product knowledge and gathering relevant supporting information on businesses that promote sustainability (Oh and Abraham, 2015). In addition, to increase consumers' advocacy for the usage of organic cotton in apparel products, information on the beneficial features of organic cottons, sustainable production processes, and the potential benefits to the environments and the workers involved in the supply chain of global organic cotton production needs to be well communicated to consumers who are also tuned into sustainability and fair trade. It is then critical that products with such special claims are outlined with a manufacturing story, in order to inform consumers with product awareness and justify their additional price premiums. 
Peterson et al. (2012 cited in Oh and Abraham, 2015) found that participants of the study with self-declared awareness on cocological impacts of textiles and garment production processes, established convictions on animal rights, and knowledge of organic food products valued wool products higher than synthetic-acrylic products. Further, they indicated that an environmental tag alongside an animal welfare claim could create more value than a basic organic label. It is clear that not only do product fabrications and fibres also represent another strategic cue in product labelling, additional ethical manufacturing information on top of the existing ones seem to be more desirable for customers.

Yiridoe et al. (2005 cited in Oh and Abraham, 2015) reported that the absence of prior knowledge was the chief reason that customers are not buying organic foods and are also unable to recognise the features of organic foods from the conventional alternatives. Laureati et al. (2013 cited in Oh and Abraham, 2015) also found that subjects who were more informed about environmental sustainability had higher expectations toward organic yogurts as they perceive them to be better than conventional ones. Hustvedt and Bernard (2010 cited in Oh and Abraham, 2015) investigated how consumer willingness to pay price premiums increased for apparel products when labour-related information was added. In their investigation, consumers with positive attitudes toward social responsibility and fair trade increased the amount of money they were willing to pay for apparel products containing labour-related information. Hence, when consumers are thoroughly informed about the product's content, the manufacturing story of its processes and supply chain stakeholders, there is higher propensity of customers in making a purchase.

Rao and Sieben (1992 cited in Oh and Abraham, 2015) earlier examined how other factors such as consumer knowledge on garment product quality, functional performance relationships, brand story, store information, user experience information, and personal associations relate to retail price acceptance. Therefore, further research into these other 
critical variables would aid in the understanding of the dynamics that businesses could utilise in order to manipulate consumption. However, according to Oh and Abraham (2015), on the case study of organic cottons, even though the benefits of using organic cottons instead of regular cottons in apparel products are well acknowledged among consumers, they tend to choose regular cotton clothing over organic cotton clothing when higher prices are associated with organic cotton clothing. Organic cotton producers and retailers need to improve organic cotton production and trading processes to provide organic cotton clothing at more affordable prices. The price factor still remains at play in this customer purchase decision-making dynamic.

Respondents in Joergens' (2006) study indicated that although more information is desired on the product label, they also identified that product prices still maintains as the primary deciding factor for consumption behaviours. According to a respondent in the research, the conditions under which the goods were produced were not the initial considerations. Rather, the choice for the purchase of fashion clothing, the price must be reasonable and this foregoes ethical issues. According to Joergens (2006), it is clear that customers would rather abandon ethical considerations when making purchases in order to buy more items with their money. Price of the product remains a leading factor on this aspect.

In recent years, there is an increase of consumer demand for products that emphasise a "custom, artisan, or craft aesthetic." Businesses respond to this demand by the putting forward of merchandise that elevates the strategy of a smaller production run with a customised focus - "small flourishes and touches that appear handmade are quite effective at delivering this effect" (Hi-Tech Printing and Labelling, cited in PRNewswire, 2015). 


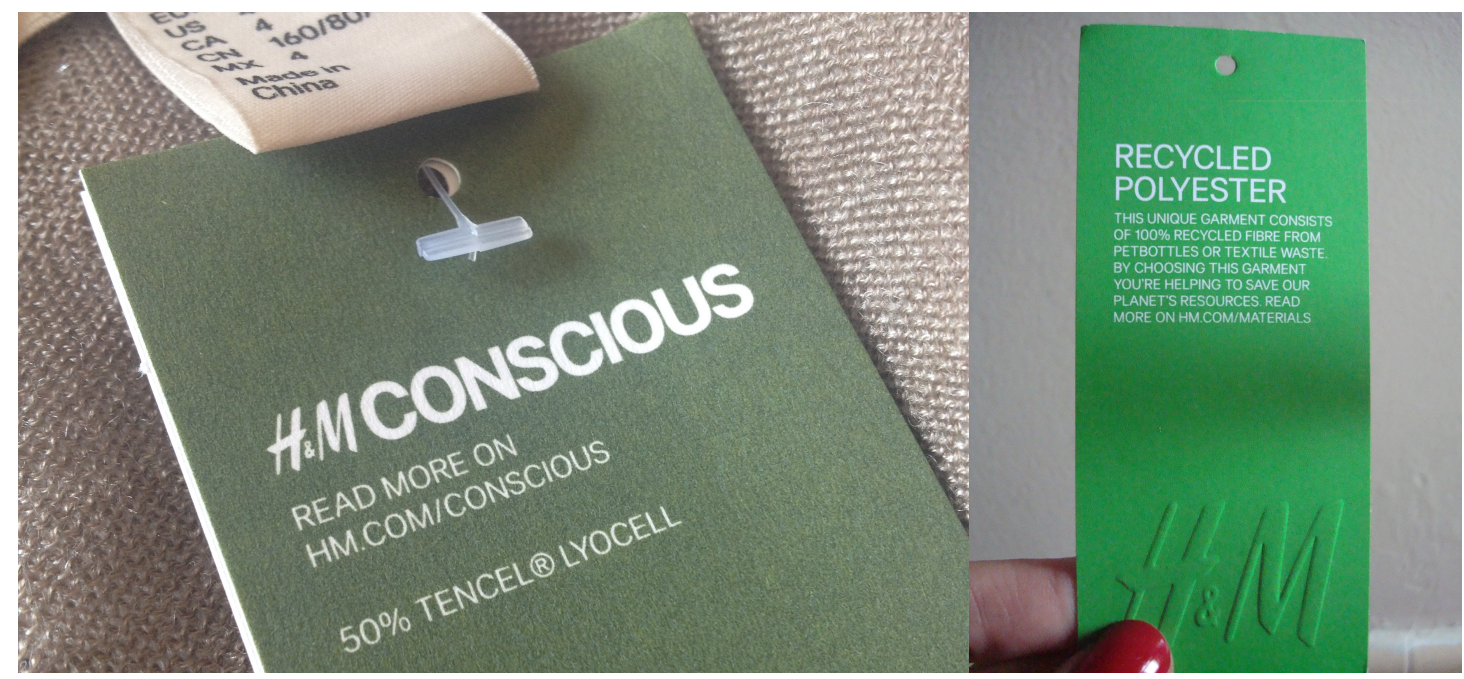

Exhibits 4 and 5: H\&M's product label, laden with green verbal and visual cues.

Also, as established earlier, for the informed and concerned consumer, certain fibres are admittedly more desirable in the market. Therefore, they are communicated more prominently (Exhibits 4 and 5) in size. In Exhibit 3, even though Tencel®Lyocell made up $50 \%$ of the fabric composition, the other $50 \%$ was not revealed on the H\&M hang tag. The purpose seemed to only be to emphasise the presence of Tencel®Lyocell in the product. The hang tag in image 4 demonstrates a similar concept by marketing recycled polyester made from PET bottles as the key 'green' ingredient in the product. This recycled polyester material story presented by the brand in this label corroborates with the strategy that was concluded in the research by Hustvedt and Bernard (cited in Oh and Abraham, 2015) of the commercial value in emphasising labour and manufacturing related information in the product tag.

According to Tang et al. (2004), green labels are critical, in that they provide an avenue for customers who are ecologically-aware to declare their individual expectations in the market. In their research, it was found that both visual and literal communication had distinct cumulative influence on the purchase of the merchandise. Therefore, it would be reasonable to expect information to become increasingly visual. 


\subsubsection{Evolution from literal to visual cues in product labelling}

With reference to the secondary literature cited in this paper, we have established that the product labelling practice in fashion has evolved beyond the role of information, into the function of marketing strategy. Product information for fashion labels have also evolved from literal to visual communication.
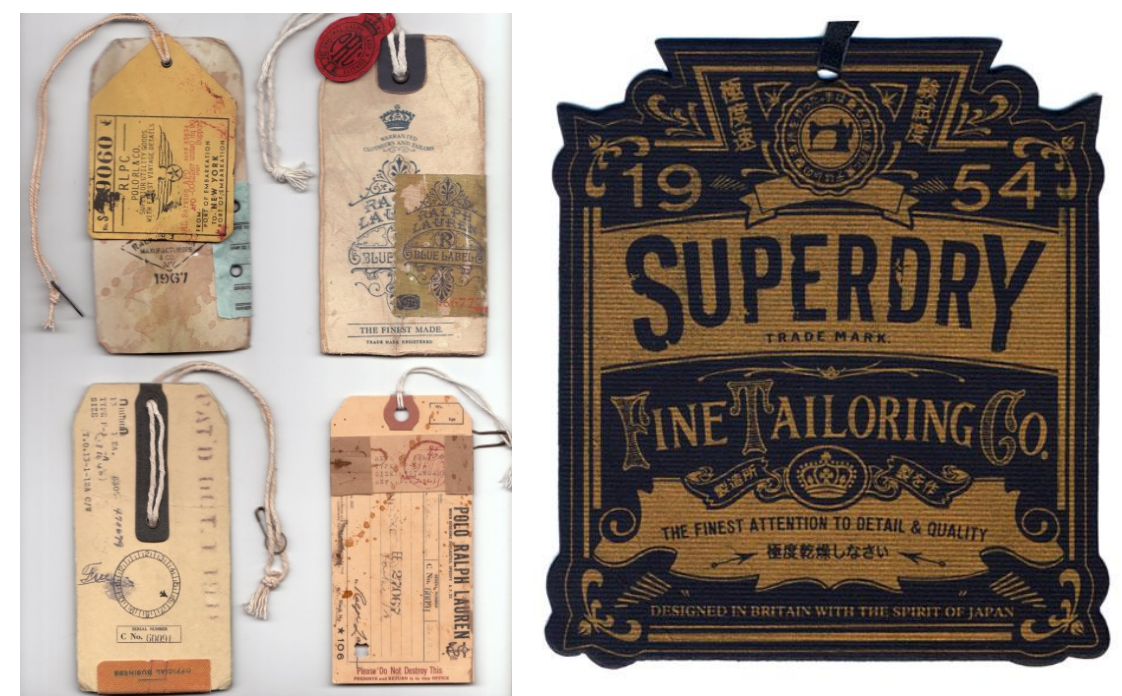

Exhibits 6 and 7: Design details in product label visually communicate the idea of age and establishment

Exhibits 6 and 7 shows the apparent distressed surface treatment of the product hang tags from the Polo Ralph Lauren and SuperDry brands respectively. For the Ralph Lauren product hang tags, they were designed to mimick the look of vintage luggage tags. This strategy was probably designed to insinuate the image of a brand that is historical and wellestablished, indicating product reliability. This is similar to the strategy used at SuperDry. As a brand that only surfaced in 2003, the "1954" label seems deceptive. Apart from the clear verbal message, the archaic layout of the label design, typefaces, and monochromatic colour schemes employed, all attempted to direct the consumer to the message of brand establishment and age. 


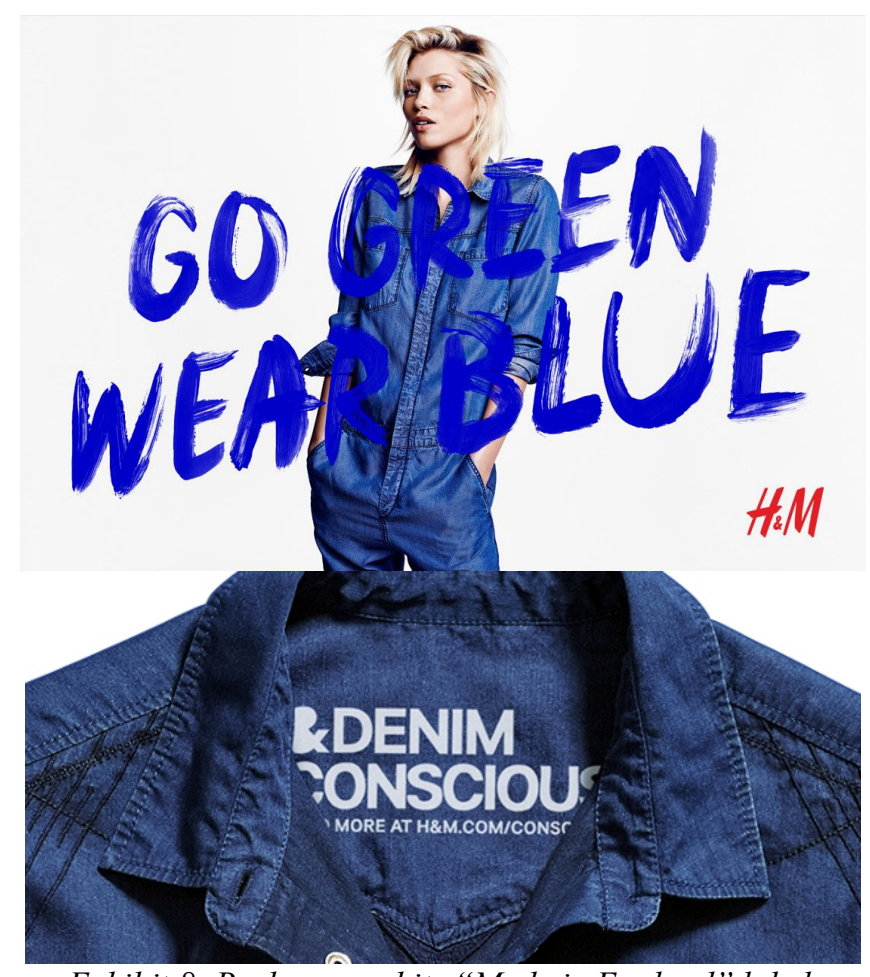

Exhibit 8: Burberry and its "Made in England" label.

Exhibit 8 shows a marketing exercise by $H \& M$ to promote the purchase of their "conscious" denim products. Apart from using the word "green" as an inference to the ecologically ethical nature of the product, the marketing team also cleverly utilised both literal and visual cues that aided in the association of blue denim with "green" concepts. The strategic visual tool is apparent in this instance. Therefore, even without truly "green" attributes in certification or official environmental product labelling or certification tags, visual tools on product labels today increasingly serve the same purpose. 


\subsubsection{Labelling standards in the industry}

With the relentless rise of the fast fashion phenomenon, it seems that accurate ethical labelling has become even more critical. Information labelling structures have grown to become increasingly diverse, and hence it has become challenging, but pressing to construct a global system of aligned labelling regulations.

The FTC of the US seems to have a very elaborate regulation in labelling requirements for clothing and textiles. With the objective to "Protect America's Consumers", its regulations under the Textile and Wool Acts cover most textile products (Exhibit 9), including "clothing, except for hats and shoes, handkerchiefs, scarves... curtains and casements, draperies... cushions, (as well as) all fibres, yarns and fabrics." Regardless of product labelling rules relating to consumption ethics or health and safety, the boundaries set by the FTC is well-defined, as evident below (Exhibits 9 and 10):

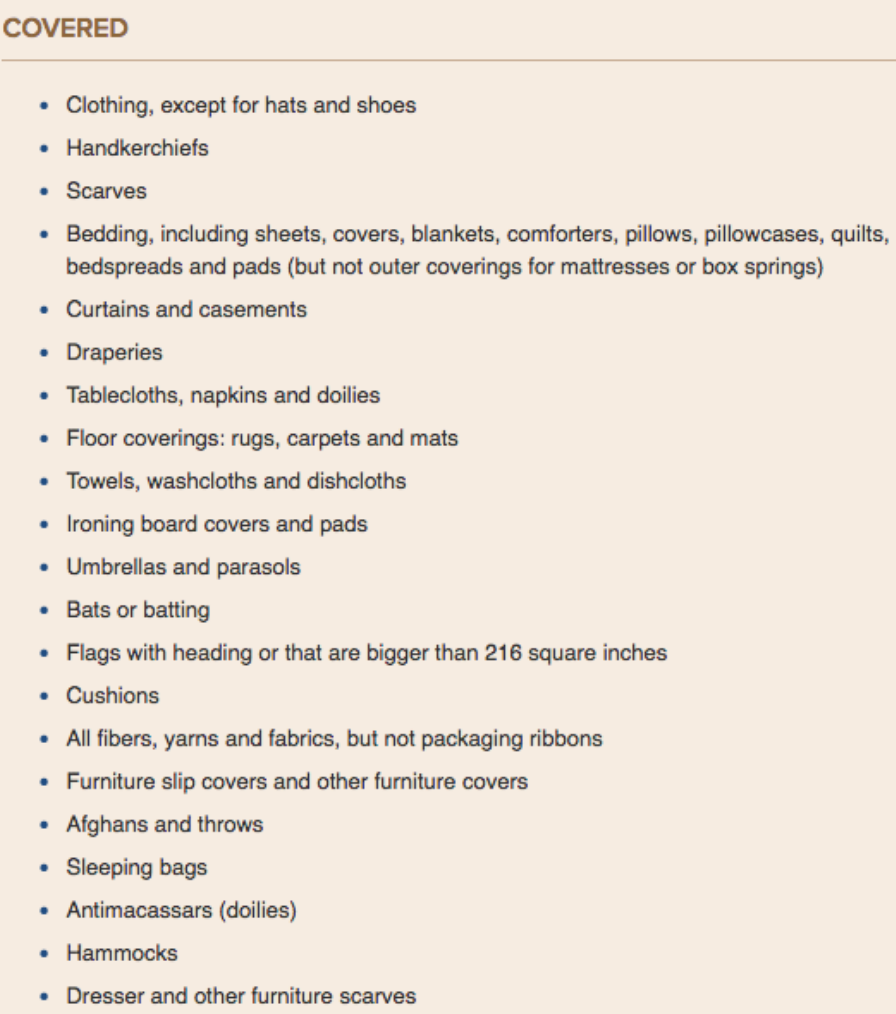

Exhibit 9: Elaborate coverage of textile products by the FTC. 


\section{- Fiber Content}

- Exceptions to the Fiber Disclosure Requirement

- Sectional Disclosure of Fiber Content

- Pile Fabrics

- Fiber Names

- Premium Cotton Fibers -- Pima, Egyptian, Sea Island, etc.

- Wool Fiber Names

- Fiber Trademarks

- Products Containing Unknown Fibers

- Sale of Remnants and Products Made of Remnants

- Marking of Fabric Samples or Swatches

- Tolerances for Fiber Content

- Country of Origin

- Imported products made entirely abroad

- Unqualified "Made in U.S.A." labels

- Products made in U.S.A. with imported materials

- Identification of processing or manufacturing that takes place in the U.S. and abroad

- Country names

- One step removed rule

- Country of origin in mail order advertising

- Identification of Manufacturer, Importer, or Other Dealer

- If you use a company name

- If you use a Registered Identification Number (RN)

- How to get an RN

- How to identify the company holding a particular RN

- How to update RN information

- Replacing another company's label with your own

\section{- Mechanics of Labeling}

- Label placement and attachment

- Special exception for hosiery sold in packages

- Special requirements for socks

- Other products sold in packages

- Products with two or more items of the same fiber

- Products with two or more items of different fibers

- Bolts of cloth

- Advertising and Catalogs

- Ads

- Catalogs

- Continuing and Separate Guaranties

- Record Keeping

- Summary of Fur Labeling Requirements

- Label information

- Mechanics of labeling

- Invoices and advertising

- Exemption

- Record keeping: Continuing and separate guaranties

- Enforcement of the Textile, Wool, and Fur Rules

- For More Information

- Your Opportunity to Comment

- Endnotes

- Appendices

- FTC Address \& Telephone Numbers for questions about the Textile, Wool, and Fur Rules

- Generic Names for Manufactured Fibers 16 CFR § 303.7

- ISO Names Permitted, Although Not Listed in Textile Rules

Exhibit 10: Elaborate labelling requirements by the FTC. 
Japan is also another developed economy that has an elaborate system of labelling requirements (Exhibits 11a, 11b and 11c). As indicated in the table of labelling requirements below, product categories are also widely covered. With reference to the last column labelled "Additional items", the names of the labellers and contact addresses are mandatory, indicating strict regulations for responsible product labelling for soft goods.

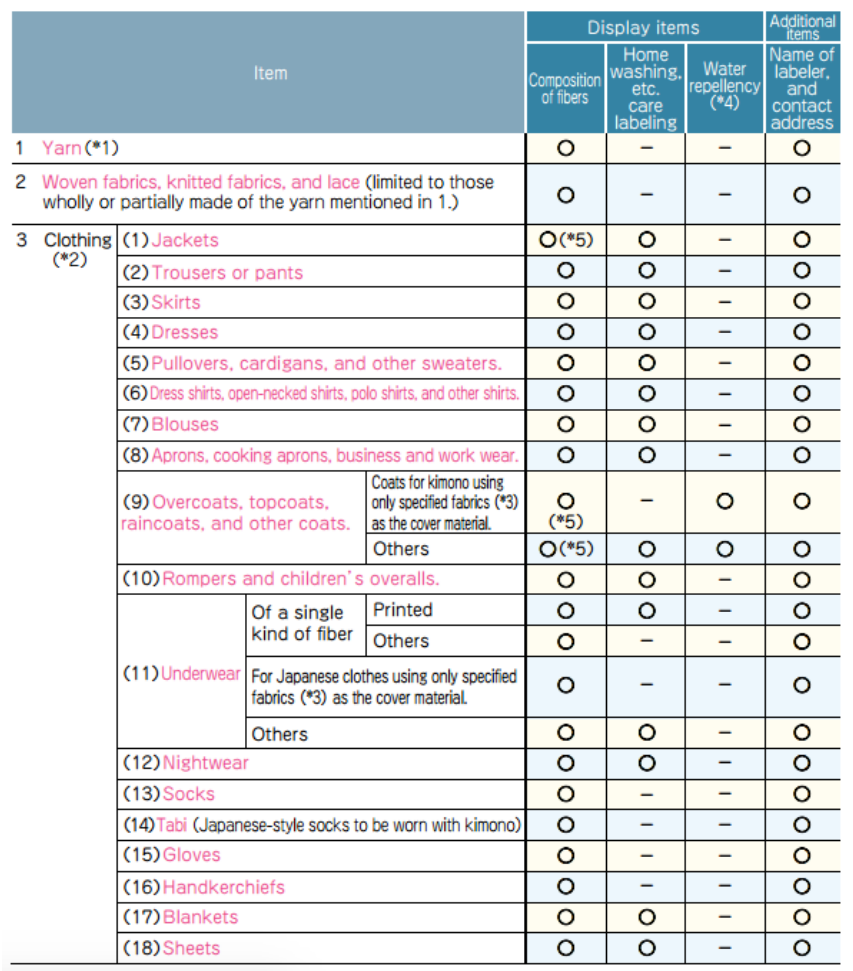

Exhibit 11a: Elaborate labelling requirements in Japan.

\begin{tabular}{|c|c|c|c|c|c|}
\hline \multirow{2}{*}{\multicolumn{2}{|c|}{ Item }} & \multicolumn{3}{|c|}{ Display items } & \multirow{2}{*}{$\begin{array}{l}\text { Addititional } \\
\text { Nemns } \\
\text { Name of } \\
\text { labeler. } \\
\text { and } \\
\text { contact } \\
\text { address }\end{array}$} \\
\hline & & $\begin{array}{l}\text { Compostion } \\
\text { of fibers }\end{array}$ & \begin{tabular}{|c|} 
Home \\
washing. \\
etc. \\
care \\
labeling
\end{tabular} & $\begin{array}{l}\text { Water } \\
\text { repentercy } \\
(-4)\end{array}$ & \\
\hline \multicolumn{2}{|c|}{ (19) Towels and tenusui (Japanese-style hand towels) } & 0 & - & - & 0 \\
\hline \multirow{2}{*}{\begin{tabular}{|l|} 
(20) Haori (short coats to \\
be worn over kimono) and \\
kimono (traditional \\
Japanese clothes)
\end{tabular}} & 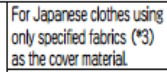 & 0 & - & - & 0 \\
\hline & Others & 0 & $\mathrm{O}$ & - & 0 \\
\hline \multicolumn{2}{|c|}{ (21) Mufflers, scarves, and shawls. } & 0 & - & - & 0 \\
\hline \multicolumn{2}{|l|}{ (22) Dressing gowns } & 0 & 0 & - & 0 \\
\hline \multicolumn{2}{|l|}{ (23) Curtains } & 0 & 0 & - & 0 \\
\hline \multicolumn{2}{|c|}{\begin{tabular}{|l} 
(24) Carpets (limited to those with piles) \\
\end{tabular}} & 0 & - & - & 0 \\
\hline \multicolumn{2}{|c|}{\begin{tabular}{|l} 
(25) Coverlets (limited to those made of towels) \\
\end{tabular}} & 0 & 0 & - & 0 \\
\hline \multicolumn{2}{|c|}{\begin{tabular}{|l|} 
(26) Futon (Japanese-style quilts or mattresses) \\
\end{tabular}} & 0 & - & - & 0 \\
\hline \multicolumn{2}{|c|}{\begin{tabular}{|l|} 
(27) Blanket covers, futon covers, illow covers and bed spreads \\
\end{tabular}} & 0 & $\mathrm{O}$ & - & 0 \\
\hline \multicolumn{2}{|l|}{\begin{tabular}{|l} 
(28) Table cloths \\
\end{tabular}} & 0 & - & - & 0 \\
\hline \multicolumn{2}{|l|}{\begin{tabular}{|l} 
(29) Neckties \\
\end{tabular}} & 0 & 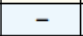 & $\begin{array}{cc}- & \\
\end{array}$ & 0 \\
\hline \multicolumn{2}{|l|}{ (30) Swimming wear } & 0 & - & - & 0 \\
\hline \multicolumn{2}{|c|}{ (31) Furoshiki (Japanese-style wrapping cloths) } & 0 & - & - & 0 \\
\hline \multicolumn{2}{|c|}{\begin{tabular}{|l} 
(32) Obi (Japanese-style sash belts for kimono) \\
\end{tabular}} & 0 & - & - & 0 \\
\hline \multicolumn{2}{|c|}{\begin{tabular}{|l} 
(33) Objijime (sash fasteners) and Haori strings \\
(3)
\end{tabular}} & 0 & - & - & 0 \\
\hline
\end{tabular}

Exhibit 11b: Elaborate labelling requirements in Japan. 


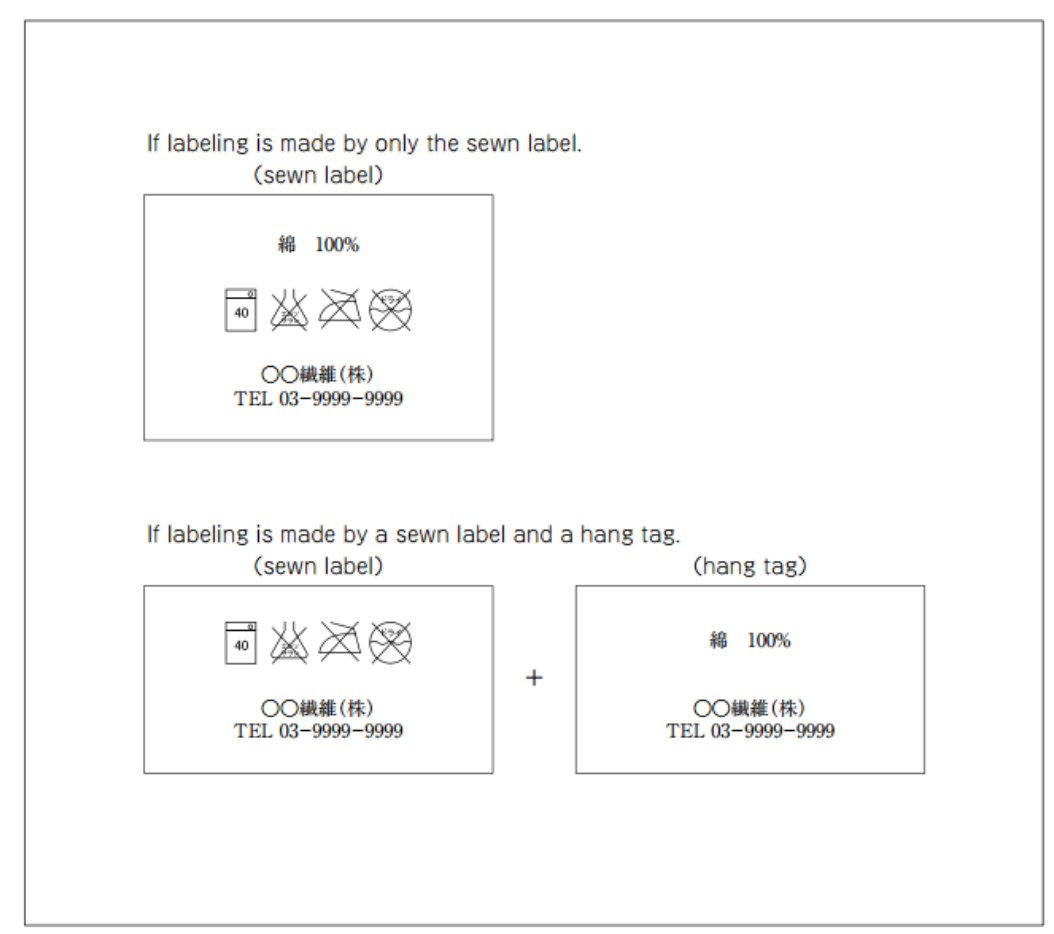

Exhibit 11c: Elaborate labelling requirements in Japan.

While labelling standards in economically more advanced economies like the US and Japan are well-established and are highly structured, their primary aim is towards transparency and responsibility in the labelling of information. However, there is still a lack of emphasis on issues relating to labels that claim ethical implications from the purchase of a product.

\subsubsection{Implications of a mandatory COO label}

In 2010, the European Parliament voted for the implementation of a mandatory COO in product labelling. According to Simon Bennet (2011), one of the partners at the Fox Williams Group, an agency that specialises in the fashion law and trade practice, based in the UK: The purpose of this legislation was to make it obligatory for European imports from the clothing, textiles and footwear categories to bear COO indications in order to ensure transparency of their production locations. This implementation would lead to varying impacts on the different sectors of the fashion market. 
Luxury brands which are reliant on geographical prestige in sourcing for materials, vendors and factories would benefit from the new legislation, as it shows promise in anticounterfeiting strategy. Brands often use the $\mathrm{COO}$ as an advertising and marketing tool $(\mathrm{Wu}$, $\mathrm{Ju}$ and Dodoo, 2016), utilising the cultural and historical references to quality and craftsmanship which a particular area suggests to a consumer, linking the product to either positive or negative connotations with respect to their country reference (Chattalas, Kramer \& Takada, 2008 cited in Wu et al., 2016). For instance, since Italy is renowned for its craftsmanship in leather goods, the "Made in Italy" label would signify the premium quality that is associated with it. Also, given the reputation of Scotland in cashmere, tweed, as well as wool and lace production (Chesters, 2014), a Made-in-Scotland label would represent the premium COO tag for woollen or cashmere garments. This supports prior research, which indicated that references to countries can be either stereotypically functional or emotional (Peabody, 1985; Leclerc, Schmitt \& Dubé, 1994; Verlegh \& Steenkamp, 1999 cited in Wu et al., 2016). Therefore, Bennet (2011) makes a reasonable statement that heritage brands trade on the emotional concept of patriotism, and hence it would be sensible for these brands to champion the $\mathrm{COO}$ legislation, as there is promise for consumer perceived value in their merchandise.

At the other end of the market spectrum, high street brands would criticise this labelling as unnecessarily expensive. This is because their loyal customers are characteristically less concerned with the origin of their purchase but accord a bigger emphasis on affordability rather than on the prestige of their clothes. Nonetheless, these customers will be compelled to absorb the costs, because inevitably, the additional labelling will increase the costs of production, and those price increases will be trickled on to the consumer (Bennett, 2011). This suggests that due to the added costs, additional labelling 
correlates to a higher product price built at the expense of the customer, providing an indication of how these brands would not support such a change in legislation.

Also from the standpoint of regulation and legislation, there are implications in terms of the enforcement of these laws. The COO labelling becomes a technical compliance requirement for international trade, and this increased policing in trading standards could make the resource flow within the supply chain more cumbersome (Bennett, 2011). However, from a global perspective, this COO proposal by the European Commission in 2005 sought to rectify a number of critical issues related to product labelling of this nature: “(1) Primarily, it is argued that it is in the interests of the consumer for the origin of products to be transparent, following concerns over the mounting incidence of misleading use of origin indications. As there is currently no legislation regulating origin labelling in the EU, consumers may be deceived regarding the true origin of products, and thus unable to make an informed decision as to their buying habits. (2) There are also ethical arguments for this transparency, as some consumers would avoid buying products that had been produced in certain countries, perhaps where there is a poor human rights record, or a political system with which the consumer disagrees. Origin labelling would in theory allow consumers to be able to buy their clothes with absolute certainty as to their provenance. (3) Further to this, as the EU's trading partners such as US, China and Japan already have in place country of origin legislation, there is an argument that Europe ought to be placed on an equal footing with its partners" (Bennett, 2011).

Nevertheless, critics maintain that this proposal acts as a "protectionist and bureaucratic" strategy that creates a trade barrier: (1) according to the Commission's review of the proposal, COO labelling could layer up additional costs of up to US\$2.40 to articles of fashion such as apparel and footwear. Manufacturers would also need to absorb additional costs on logistics; (2) in the production trail, goods are subject to various stages of value 
adding in factories of multiple countries, it may therefore be challenging to designate the specific place in which a product is manufactured, and this would result in a situation where labelling only one COO may be just as misinformed as having none labelled; (3) also, the EU and its partners in trade have misaligned rules regarding $\mathrm{COO}$ labelling. Companies which produce in developing countries but market their products in both EU and non-EU countries will find this logistically and financially challenging; and (4) the systems put into place to ensure the compliance of these standards would create further unnecessary levels of administration (Bennett, 2011).

The challenges that this renewed regulation of mandatory COO labelling would impose on foreign imports have led to criticism that this is merely an EU protectionist strategy against cheap external imports. For instance, some references are associated with merchandise produced in East Asian factories which may suggest the lower quality control of the products manufactured. COO labelling would create the situation of widespread decrease of sales volume in products from such origins - a phenomenon created from the result of stereotype within the industry (Bennett, 2011).

In a society awash in marketing messages, Joy Nazzari (2015) states that brand provenance is a critical strategy in creating desire in consumers, and influencing purchase. Nazzari (2015) cites the example of mail order clothing business Charles Tyrwhitt that was established in 1986, without any heritage story in shirting. The company then acquired "100 Jermyn Street", an iconic address with a powerful provenance, renowned for shirt-making supplying garments to the British royal family. Because of this strategic association to an address with provenance, the business grew to become one of the most celebrated shirtmakers in the UK. Therefore, for brands lacking in genuine provenance, there are three ways to manipulate this strategy, according to Nazzari (2015): “(1) hijack provenance by acquiring 
a brand that has a true origin story; (2) manufacture provenance through clever marketing; or (3) reframe your message altogether and tell a different story."

Provenance could be hijacked through acquisition. Chinese companies have bought over European brands like Pirelli, Club Med, Volvo and Bordeaux vineyards, from the late 1990s. This phenomenon was due to the foresight of the Chinese businessmen's recognition of the weakness in provenance of China outside of manufacturing and technology. In the chocolate industry, provenance belonged to Belgium and Switzerland. Godiva originally founded in Brussels, Belgium in 1926, for example, was acquired by Turkish Yildiz Holding in 2007. However, many customers still believe that they are still buying into Belgium's chocolate heritage.

Brand provenance could also be manufactured. The Häagen-Dazs brand for example, originated from the US. The brand name was created to sound Norwegian, thereby associating to the dairy produce provenance of Norway. Because of this effective strategy in the marketing of the brand provenance story, today the brand represents a multimillion-dollar global business owned by transnational corporation Nestlé.

One of the most successful reframings of provenance was achieved by Shinola, a new watchmaker, bicycle and leather goods company founded in 2011, that has taken the historic shoe polish brand name and associated it with Detroit, a heritage region of Motown music and auto-manufacturing, to create a successful lifestyle company. The company, owned by a venture capital firm born from Texas Instruments, is now selling over 500,000 models a year.

Although it is acknowledged that COO strategies are a commonly used tool in fashion product labelling, it is important to remember that the desirability factors of the manufacturing countries change with time. In the 1990s, Portugal had the reputation as the “China of Europe", providing low quality, low production costs in mass production, mainly supplying to the European markets. After Portugal joined the European Union, its national 
manufacturing sector experienced an increase in labour costs. Simultaneously, the Chinese, Korean, Vietnamese, Brazilian and North African producers improved in terms of quality and adaptability. The period of transition involved the replacement of low quality producers with fast-growing high-end factories (Mellery-Pratt, 2015).

In the preceding literature review, we have identified some common strategies executed by fashion businesses in their product labelling practices, such as transparency, country effects and verbal/visual green cues. This research has identified several information gaps that requires attention and further investigation. Primarily, this research should seek to understand if current labelling practices, especially the prominence, visibility and frequency of the strategic information, identify with the pattern that was presented by scholars.

Also, from secondary research, we can acknowledge the significance of country effects in product labelling. For further investigation, this research can explore how products labelled with highly desirable production origins (COO), affect the other country information labelling, especially the country of establishment (COE) and the country of design (COD). Finally, another information gap that this research will address is in regard to the presence of visual green concepts on product label marketing, regardless of the apparent absence of any parallel verbal green message. 


\subsection{Research Questions}

As indicated, there are three areas of further investigation that this research will attempt to undertake in primary analysis: (A) the prominence, visibility and frequency of strategic information content; (B) the significance of, and the relationships between country effects in labelling; and (C) the relationship between green visual cues with parallel verbal declarations on the product label.

Because of the rising prevalence in information transparency on the product label, it is critical for consumers to acknowledge the strategies of product content that have been made available. This research seeks to understand the climate of labelling practice in the markets, in that how certain strategic information perform in terms of their degree of emphasis on the label. Therefore, the following research questions have been formulated to frame the first area of enquiry:

RQ1a: Of the information present, what are the most prominent and most visible element of the product label content?

RQ1b: Of the information present, which element is communicated most frequently on the product label?

From the review of literature sources, this research understands that there exists an undisclosed consumers' country desirability scale when it comes to making purchase decisions. This paper has also indicated that labelling a highly desirable country as the COO is a strategy that is largely applicable for brands that have an undesirable country effect in their brand origin (COE). This strategy is true in the reverse circumstance. Hence, this research aims for a further corroboration in its primary data:

RQ2a: Is there a difference in other country-effects labelling (i.e. country of establishment and country of design) for products labelled with a COO on the low desirability scale, against products labelled with a COO on the high desirability scale? 
RQ2b: Are product labels with COOs from Western countries emphasised more frequently than products labelled with COOs from other countries?

From the literature review, this research has acknowledged an increasingly prevalent phenomenon of product labelling with green visual cues, in order to insinuate concepts relating to responsible production processes. This could be manifested regardless of the presence of true verbal green labels. The following research question would help in the further investigation of this phenomenon:

RQ3: Are most product labels supported with visual cues that communicate the green concept, regardless of the absence of verbal green attributes?

\subsection{Methodology}

\subsubsection{Sample}

In order to make the selection for the required sample of fashion product labels for this content analysis, samples from the Robinsons department store, where fashion products were readily accessible, were collected. Because this initial sample from the department store admittedly only represented a rather narrow targeted consumer market, this research expanded the cross-market variety of this sample by including product labels from several brands in the mid to higher market range, such as Louis Vuitton, Calvin Klein, BritishIndia and Brooks Brothers. Several of Southeast Asia's most popular fast fashion brands, such as Mango, H\&M, Cotton On, Uniqlo and Zara, were included into the sample to be analysed. Therefore, this sample selection represents product labels from brands across several consumer markets.

The qualitative content analysis process begins with the selection of a sample size of 60 fashion product labels. To ensure consistency, only product labels from similar garment types across brands were analysed. In this case, the products were top-wearing garments, 
including shirts, blouses, sweatshirts, etc. For a further analysis on the price relationship (being the chief deciding factor when making buying decisions), the sample was then distinguished from one another, based on price categories: CAT 1 (low-affordable), CAT 2 (medium) and CAT 3 (high). CAT 1 includes product items that were priced less than $\$ 89.90$; CAT 2 includes merchandise priced between $\$ 90.00$ and $\$ 149.90$; while CAT 3 are items priced above $\$ 150.00$. This price categorisation was based in Singapore dollars.

\subsubsection{Variable measurement}

The following information elements of the product label have been identified for documentation and measurement: (1) brand name; (2) brand establishment year; (3) country of establishment; (4) country of design; (5) country of origin; (6) price; (7) fabric composition; (8) brand marketing story; (9) special or "green" claims. Variables used to measure each element of content are (a) presence, (b) visibility, (c) prominence and (d) frequency. An "open-ended" remarks column has also been included to take into account any relevant anomalous observations that may aid in the further understanding of the measurements of the variables.

\section{a. Presence}

This variable measures the presence or absence of the declaration of the information element. In the coding spreadsheet, the indication of " 1 " represents that the relevant information is present; " 2 " indicates that the said information is absent.

\section{b. Prominence}

This variable measures the hierarchy of the information content. This attempts to measure the relative importance of the information by understanding in which order the said information is being presented to the customer. "Foreground" refers to the product tag or label which a customer would come into visual contact first. In this study, the "foreground" is identified to be within the actual construction of the garment, on the inner back seam of the 
neckline. In an in-store visual merchandising context, this would be the most visible product information to a customer, when hung on the hanger. The information "foreground" is also identified as the first label in the series of hangtags external to the garment. "Background", however, refers to all other product tags, both in the garment inner side seams and in the series of hangtags external to the garment.

The coding of " 1 " indicates that the information is being declared first as it appears in the foreground of the set of product tags and labels. "2" indicates that the said information appears in the background of the product labels. While " 3 " indicates that the said information appears both in the foreground and background of the product.

\section{c. Visibility}

After determining the foreground-background hierarchy of the information, the visibility variable measures the relative size of the said information element tagged on the product, with respect to other sets of information that surround it. " 1 " indicates that the information in question is larger in proportion to the other surrounding information types on the same label. "2" indicates that the said information is equal in size compared to the other information, while " 3 " indicates that the information is smaller in proportion to the rest of the other information that were tagged as part of the product label.

\section{d. Frequency}

The frequency variable measures the number of times in which the said information appears on the product labels on a single merchandise. This would help quantity the level of emphasis put into the allocation of a certain information throughout the product.

\subsubsection{Justification of the country desirability scales}

With consideration of the secondary literature presented in this paper, there exists a psychological ranking of country desirability relating to product manufacturing and quality. Several European countries, especially those in the Western Europe, tend to be highly sought 
after by the consumer. This list includes the UK, Italy, Germany, Sweden, Switzerland, Spain France etc. From the Americas, the USA and Canada are highly sought-after, for their highly desirable associations with quality industrial production. Even within the US local market, American-made products are highly regarded, largely due to national pride. Economically more developed countries in Asia, such as Japan and South Korea, remains closely related to the concept of quality and advancement in technology and innovation.

On the other end of the spectrum, this study ranks countries that are economically less developed and have a significant local industry size in manufacturing, at the lowest point on the desirability scale. Among countries with the lowest desirability scale, media coverage on known unethical working conditions in manufacturing communities is also a critical factor put into consideration for this ranking. Countries in this group include China, India, Bangladesh and Pakistan. Between the highest and the lowest ends of this scale, this research takes the liberty in making logical assumptions and estimations when according countries onto certain points of the scale. The reason for this is due to the lack of existing research on relevant coverage of country desirability levels.

The desirability scale runs numerically from "1" through "5", with " 1 " being "least desirable", at the lowest point in the scale, and "5" being "most desirable", at the highest point of the scale.

\subsubsection{Justification of the green scale}

Apart from the product label presenting verbal cues in responsible production methods, literature presented in this paper also corroborated to the concept of product labels evolving into the role of visual communication of green concepts. Therefore, it is critical that, apart from the observation of verbal claims, the study also attempts to measure visual signposts on the product label design that communicates the same green idea, regardless of the presence of technical green processes that were involved in the supply chain. 
A combination of four factors determine the green scale: presence of (1) verbal cues; (2) symbols and icons; (3) earthen/green/neutral colours; and (4) distressed surface treatment. The green scale runs numerically from " 1 " through "5", with " 1 " being at the lowest point in the scale, and " 5 " being at the highest point of the scale.

On the high end of the scale "5", all four factors (verbal, symbol, colour and surface treatment) are present on the product label. On the medium-high point, only 3 factors would be present (verbal, colour and surface treatment). On the medium point of the scale, 3 factors would also be observed (symbol, colour and surface treatment). On the low-medium point, the observation is purely visual, with only two of the factors present (colour and surface treatment). While on the lowest point " 1 " of the scale, only either one of the four factors are present on the product tag that communicates a green concept. When none of the four factors were present, there is no communication of green concepts, hence the green scale is "not applicable". 


\subsubsection{Inter-coder reliability test}

In order to ensure an additional layer of accuracy and minimise bias during the coding process, an inter-coder reliability test was carried out. This ascertained alignment of the definition of the attributes. For this inter-coder test, $25 \%$ of the total sample size of 60 were selected for this alignment, and this represented 15 of the 60 product labels that went through the process of inter-coding. Two rounds of inter-coding were carried out for additional alignment for accuracy in coding of the data.

\begin{tabular}{|c|c|c|c|c|}
\hline & $\begin{array}{l}\text { Measurement } \\
\text { of Variable }\end{array}$ & $\begin{array}{r}\text { Frequency } \\
\text { Match } \\
\end{array}$ & I/R Round 1 & I/R Round 2 \\
\hline \multirow[t]{4}{*}{ Brand Name } & Presence & $15 / 15$ & 1 & 1 \\
\hline & Prominence & $15 / 15$ & 1 & 1 \\
\hline & Visibility & $12 / 15$ & 0.8 & 0.87 \\
\hline & Frequency & $15 / 15$ & 1 & 1 \\
\hline \multirow[t]{4}{*}{ Brand Est. Year } & Presence & $15 / 15$ & 1 & 1 \\
\hline & Prominence & $14 / 15$ & 0.93 & 0.93 \\
\hline & Visibility & $13 / 15$ & 0.87 & 0.93 \\
\hline & Frequency & $15 / 15$ & 1 & 0.93 \\
\hline \multirow[t]{4}{*}{ Country of Est. } & Presence & $15 / 15$ & 1 & 1 \\
\hline & Prominence & $14 / 15$ & 0.93 & 0.93 \\
\hline & Visibility & $12 / 15$ & 0.8 & 0.93 \\
\hline & Frequency & $15 / 15$ & 1 & 0.93 \\
\hline \multirow[t]{4}{*}{ Country of Design } & Presence & $15 / 15$ & 1 & 1 \\
\hline & Prominence & $14 / 15$ & 0.93 & 0.93 \\
\hline & Visibility & $12 / 15$ & 0.8 & 1 \\
\hline & Frequency & $14 / 15$ & 0.93 & 0.93 \\
\hline \multirow[t]{4}{*}{ Country of Origin } & Presence & $14 / 15$ & 0.93 & 0.93 \\
\hline & Prominence & $14 / 15$ & 0.93 & 0.93 \\
\hline & Visibility & $12 / 15$ & 0.8 & 1 \\
\hline & Frequency & $14 / 15$ & 0.93 & 1 \\
\hline \multirow[t]{4}{*}{ Price } & Presence & $15 / 15$ & 1 & 1 \\
\hline & Prominence & $14 / 15$ & 0.93 & 0.93 \\
\hline & Visibility & $11 / 15$ & 0.73 & 0.87 \\
\hline & Frequency & $15 / 15$ & 1 & 1 \\
\hline \multirow[t]{4}{*}{ Fabric Composition } & Presence & $15 / 15$ & 1 & 1 \\
\hline & Prominence & $12 / 15$ & 0.8 & 0.93 \\
\hline & Visibility & $10 / 15$ & 0.67 & 1 \\
\hline & Frequency & $15 / 15$ & 1 & 1 \\
\hline \multirow{4}{*}{ Brand Story } & Presence & $15 / 15$ & 1 & 1 \\
\hline & Prominence & $14 / 15$ & 0.93 & 0.93 \\
\hline & Visibility & $12 / 15$ & 0.8 & 0.93 \\
\hline & Frequency & $15 / 15$ & 1 & 0.93 \\
\hline \multirow[t]{4}{*}{ Special Green Claims } & Presence & $15 / 15$ & 1 & 1 \\
\hline & Prominence & $15 / 15$ & 1 & 1 \\
\hline & Visibility & $14 / 15$ & 0.93 & 0.87 \\
\hline & Frequency & $15 / 15$ & 1 & 0.93 \\
\hline
\end{tabular}




\subsection{Findings}

RQ1a: Of the information present, what are the most prominent and most visible element of the product label content?

For prominence, we are only concerned with the consolidation of data that was coded " 1 " and " 3 ". " 1 " being in the foreground and " 3 " being in both the foreground and the background. For visibility, we are concerned with data that have been coded "1", where the said information must be larger in proportion to other information. The following illustrates the coding results from the data:
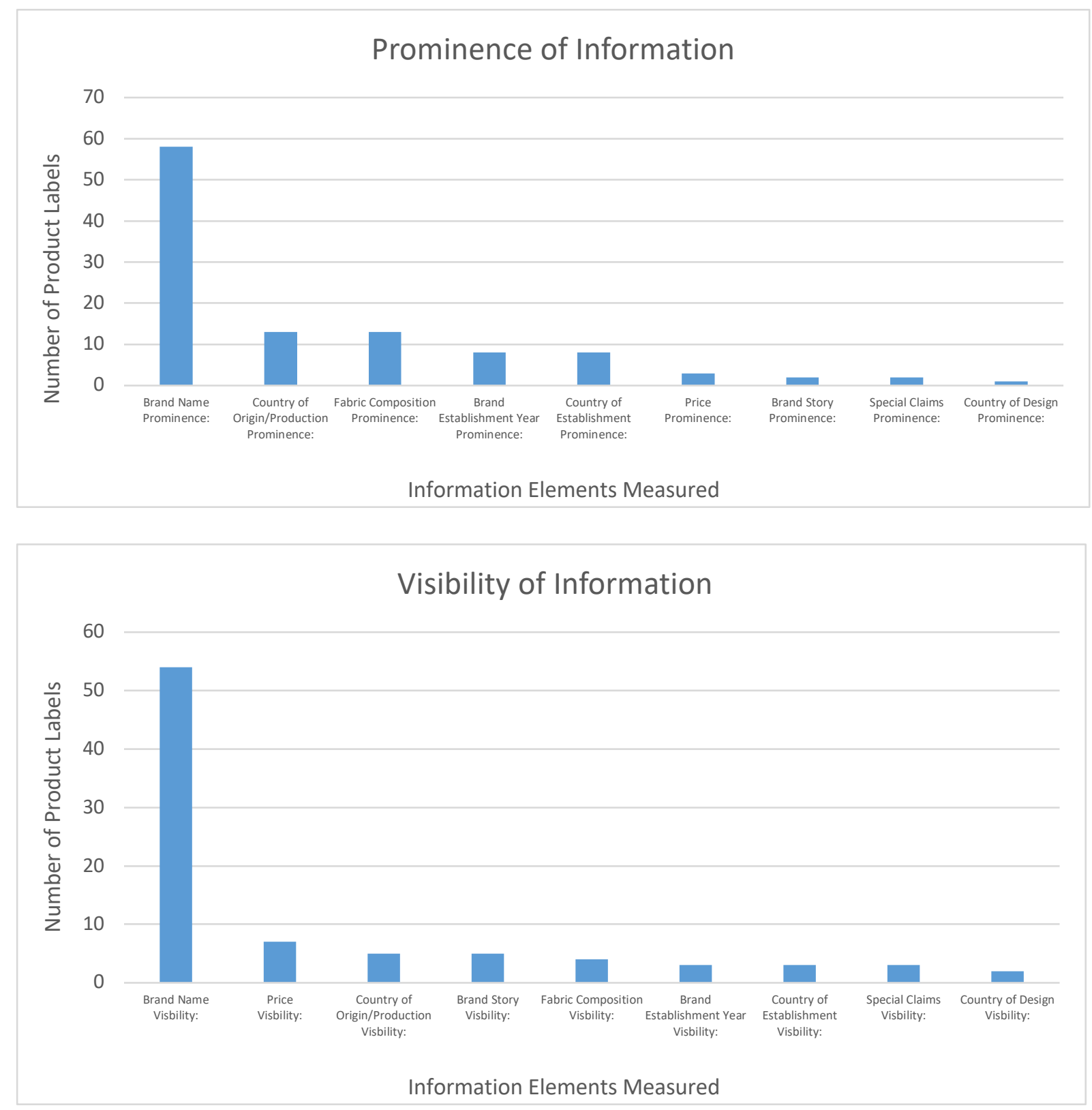
From the results in RQ1, it is clear that for both prominence and visibility, the brand name remains as the top information communicated for most of the product labels in the sample. It is also notable to acknowledge that the $\mathrm{COO}$ is ranked amongst the top three most visible and prominent information on the label. However, it seems that for special (green) claims and COD origins, they represent content that are the least emphasised in the list.

RQ1b: Of the information present, which element is communicated most frequently on the product label?

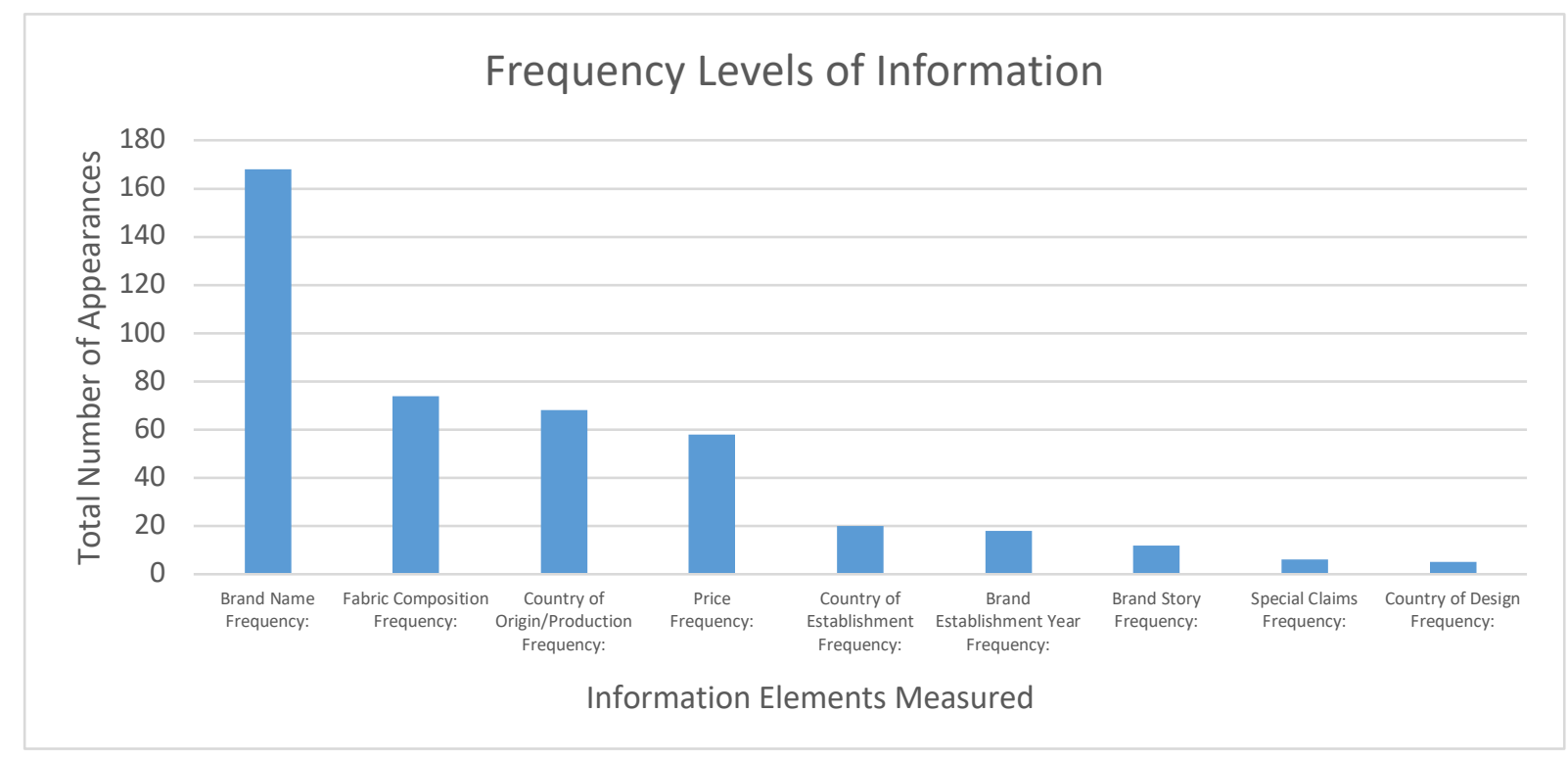

Across the all the information categories, the total cumulative frequency of brand name appearing on the product labels across the sample size of 60 yielded the highest quantity in total appearances, at 168 . The data shows that brand name is an information communicated most frequently on the product label. Again, for special (green) claims and COD, the expression of these information were not emphasised. 
RQ2a: Is there a difference in other country-effects labelling (i.e. country of establishment and country of design) for products labelled with a $\mathrm{COO}$ on the low desirability scale, against products labelled with a $\mathrm{COO}$ on the high desirability scale?

\begin{tabular}{|c|c|c|c|c|c|c|c|}
\hline \multirow{3}{*}{\multicolumn{2}{|c|}{ Cross-tab Test }} & \multicolumn{5}{|c|}{$\begin{array}{c}\frac{\text { Country of Origin }(\mathrm{COO})}{\text { Desirability Scale }} \\
\end{array}$} & \multirow[b]{3}{*}{ Total } \\
\hline & & \multicolumn{2}{|c|}{ LOW } & & \multicolumn{2}{|c|}{ HIGH } & \\
\hline & & 1 (Low) & 2 (Low) & 3 & 4 (High) & 5 (High) & \\
\hline \multirow{4}{*}{$\begin{array}{l}\text { Country of } \\
\text { Establishment } \\
\text { (COE) } \\
\text { Presence: } \\
\text { Total }\end{array}$} & 1 (Yes) & 4 & 1 & 2 & 0 & 3 & 10 \\
\hline & 2 (No) & 25 & 6 & 5 & 1 & 4 & 41 \\
\hline & & 29 & 7 & 7 & 1 & 7 & 51 \\
\hline & & \multicolumn{2}{|c|}{36} & & \multicolumn{2}{|c|}{8} & \\
\hline & Value & df & $\begin{array}{l}\text { Asymp. } \\
\text { Sig. (2- } \\
\text { sided) }\end{array}$ & & & & \\
\hline $\begin{array}{l}\text { Pearson Chi- } \\
\text { Square }\end{array}$ & $3.749^{\mathrm{a}}$ & 4 & .441 & & & & \\
\hline Likelihood Ratio & 3.534 & 4 & .473 & & & & \\
\hline $\begin{array}{l}\text { Linear-by-Linear } \\
\text { Association }\end{array}$ & 2.796 & 1 & .095 & & & & \\
\hline $\mathrm{N}$ of Valid Cases & 51 & & & & & & \\
\hline
\end{tabular}

When a cross-tab test is carried out between the $\mathrm{COO}$ and the $\mathrm{COE}$; of the 36 labelled products with a low COO desirability (scales of "1" and "2"), only 5 had the COE labelled. Of the 8 products labelled with a high COO desirability (scales of "4" and "5"), 3 had their COE labelled.

Upon performing the chi-square test, the relationship between the 2 variables COO desirability scale and COE in the distribution appears to be insignificant (0.441). 


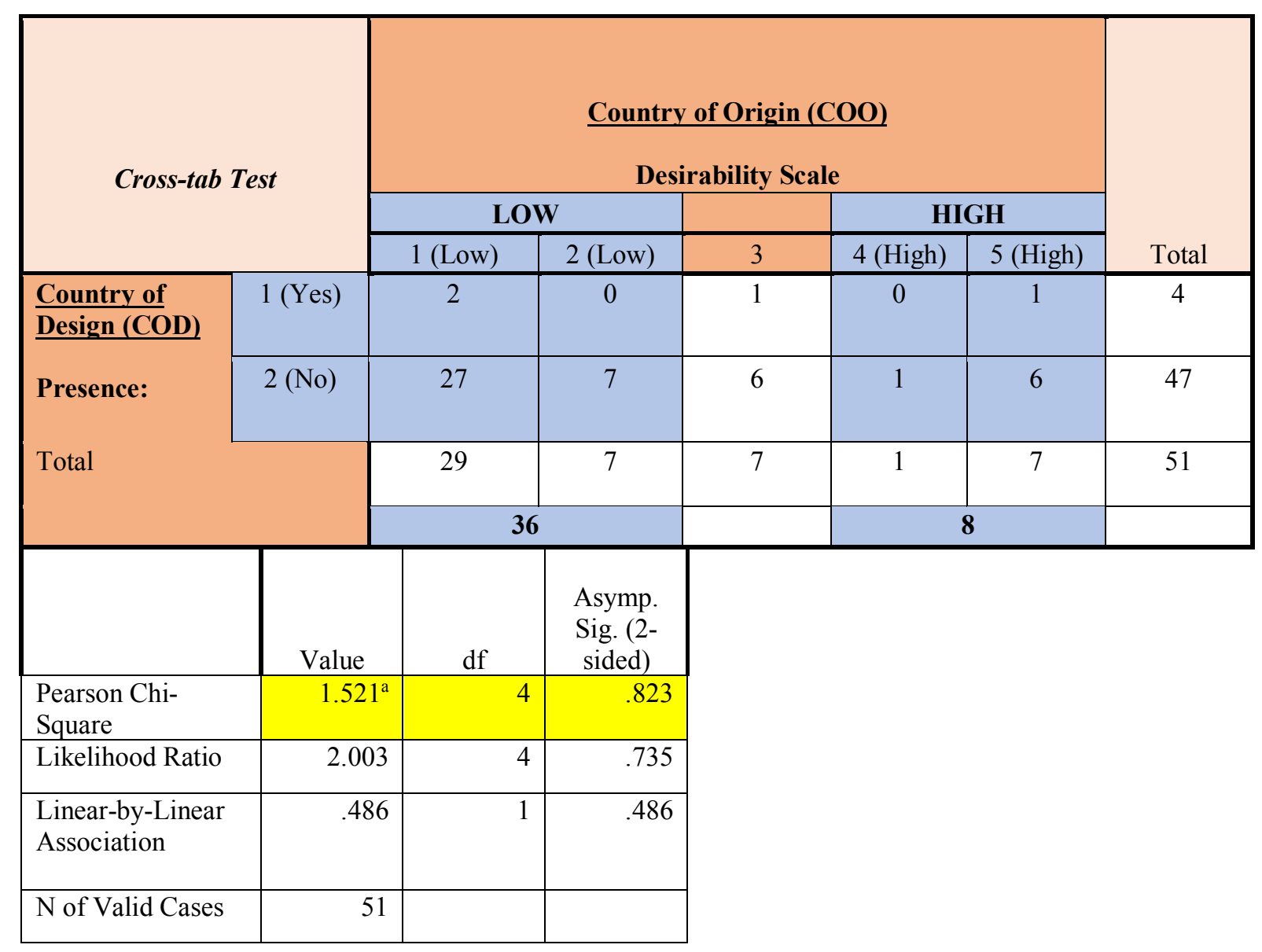

When a cross-tab test is carried out between the COO and the COD; of the 36 labelled products with a low COO desirability (scales of "1" and "2"), only 2 had the COD labelled. Of the 8 products labelled with a high COO desirability (scales of "4" and "5"), only 1 had their COD labelled.

Based on these cross-tab tables, of all the product labels that communicate the presence of $\mathrm{COE}$ and $\mathrm{COD}$, there is a comparatively higher frequency of labelled COO countries on the lowest desirability scale at "1". Strictly based on the analysis of the sample in this study, products that communicate the COE, or COD prominently, usually have a COO on the low desirability scale.

Upon performing the chi-square test, the relationship between the 2 variables COO desirability scale and COD in the distribution appears to be insignificant (0.823). 
RQ2b: Are product labels with COOs from Western countries emphasised more frequently than products labelled with COOs from other countries?

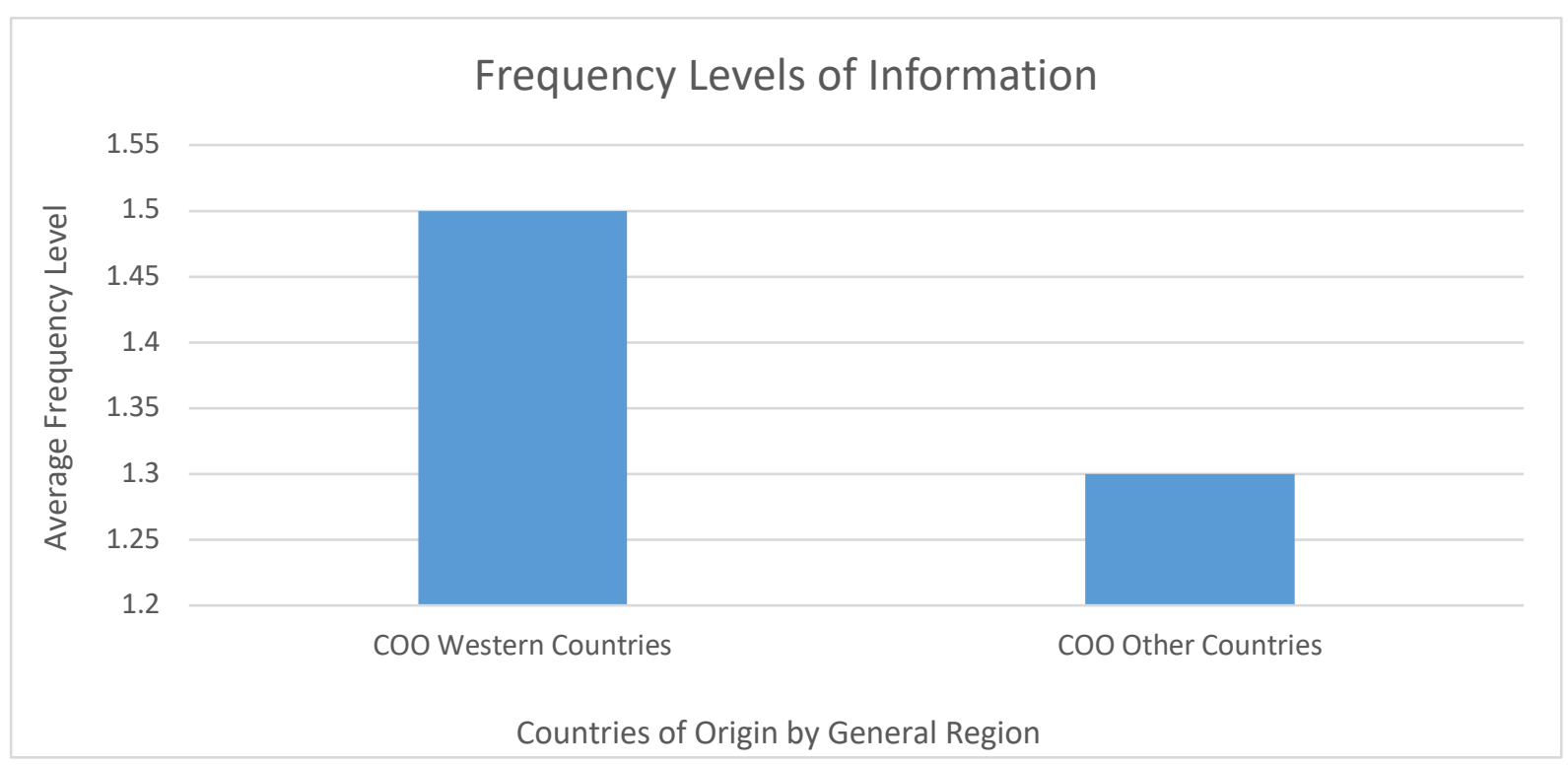

Of the total sample size of 60,51 had a COO labelled on their product tags. Out of these, products which were labelled with COOs from western countries were more frequently labelled, compared to products labelled with COOs from other countries. 
RQ3: Are most product labels supported with visual cues that communicate the "green" concept, regardless of the presence of verbal "green" attributes?

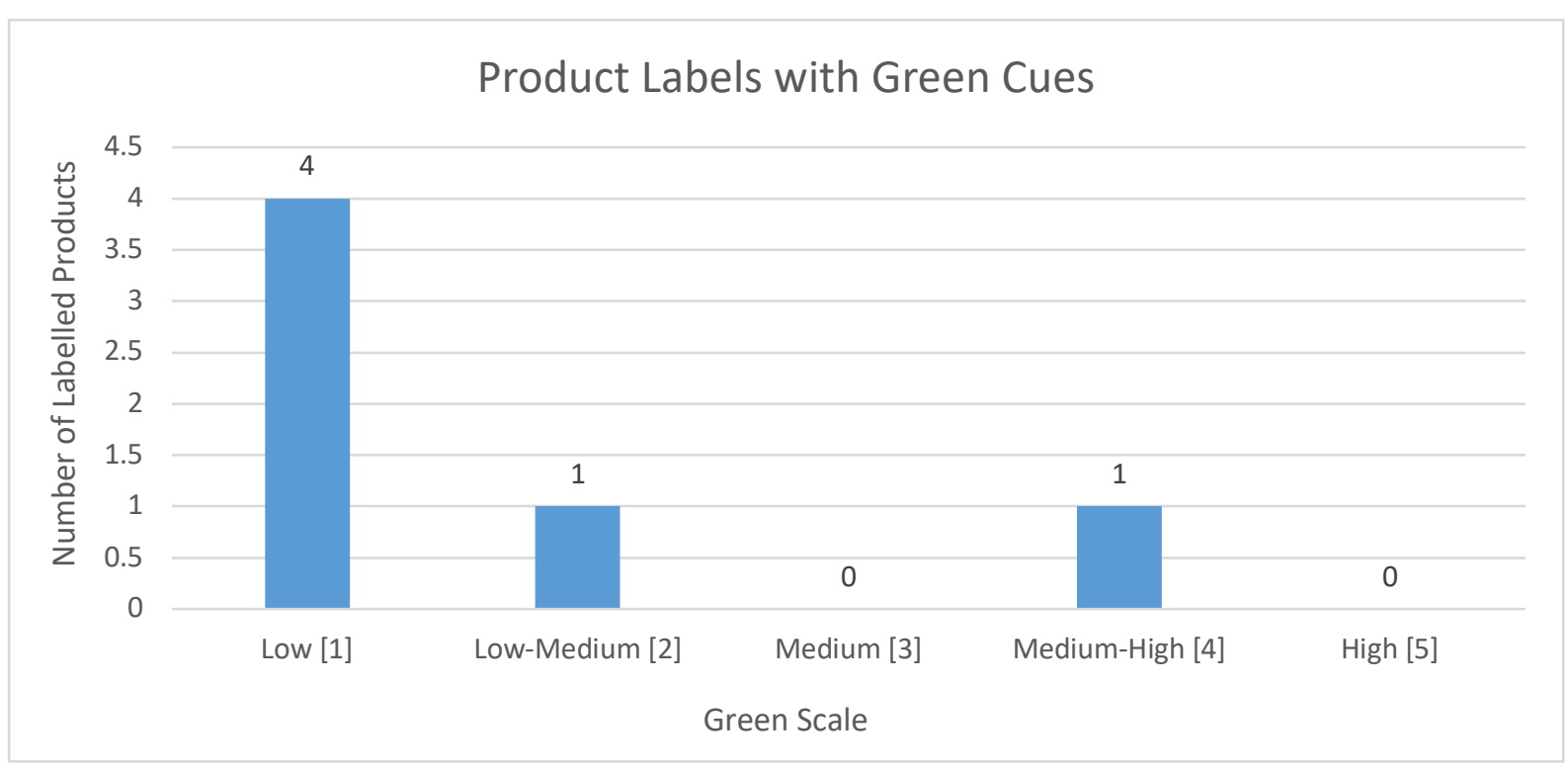

There were only 6 from the total sample size of 60 that expressed a green cue in its labelling. Out of 6 fashion products labels that portrayed a certain green attribute to their merchandise, only 1 fashion brand (with a "4" on the green scale) was observed to have parallel visual cues present, alongside with verbal ones. Therefore, strictly based on the sample in this study, it is not true that most product labels are supported with "green" visual cues, regardless of the presence of verbal "green" attributes. 


\subsection{Discussion}

\subsubsection{Primary findings from the data}

For RQ1, it remains clear that of all the information types that are present on the product label, the brand name remains as the most labelled information. The brand name is also the most prominent and visible information indicated, when compared against other surrounding information on the same label. This is logically expected, as the brand name is the single most direct communication of ownership of the product.

Also, in terms of prominence and visibility, the COO label was ranked as top three information on the product label. This corroborates with the rising importance of the production origin of the merchandise, as indicated in the literature review. The special (green) claims and COD labels lags behind the list of most prominent and visible information, indicating that they do not represent strategic tools used in labelling practice within the market.

In RQ2, of all the product labels that communicate the presence of $\mathrm{COE}$ and $\mathrm{COD}$, there is a comparatively higher frequency of labelled $\mathrm{COO}$ countries on the lowest desirability scale at " 1 ". Therefore, it can be established strictly based on the results in this sample study, that both COE and COD are emerging country-effect strategies used by businesses in diluting the effects of a negative $\mathrm{COO}$ image on a low desirability scale. The secondary research from literature is hence supported in the results of this study.

In RQ3, although this result does not corroborate with the conclusions made from the literature that green visual cues are present regardless of the presence of verbal ones; further research could explore into the other factors (e.g. geography, advancement of the domestic industry, etc.) that could affect the limited presence of "green" cues in the fashion market, apart from the apparent small sample size in this study. 


\subsubsection{Vision for the future: transparent and truthful labelling?}

As evidenced from the secondary literature review, fashion product labelling is evolving to become seemingly more transparent with the declaration of multiple information cues on the product tag. Therefore, we need to question if the future of product labelling in fashion retail would attain full transparency, and if such a future is even desirable for consumers. Clothing label HonestBy by Bruno Pieters; illustrates this future in the following exhibit images and in the Appendices.

Exhibit 12 shows a basic jersey knit t-shirt retailed at the HonestBy website. The company adopts 4 categories of information (Exhibits 13 to 16), such as (1) material information (Exhibits 13 and 14), which outlines fabric use for the main garment, as well as materials for sewing and cotton thread, size and care labels, and even the hang tag itself; (2) socio-ecological claims and third-party "green" certifications (Exhibit 15); (3) manufacturing details; and (4) price calculations, with cost of production and wholesale as well as retail markups (Exhibit 16).

Even though information in these retail situations can be fully transparent across brands in the global markets, the presented information on the product labels would be much more competitive than before, as they would be accorded the same level of emphasis. These information would simultaneously vie for the attention of the customer during his/her purchase decision-making process. Also, the challenge of a globally-aligned content structure for all product labels still remain. 


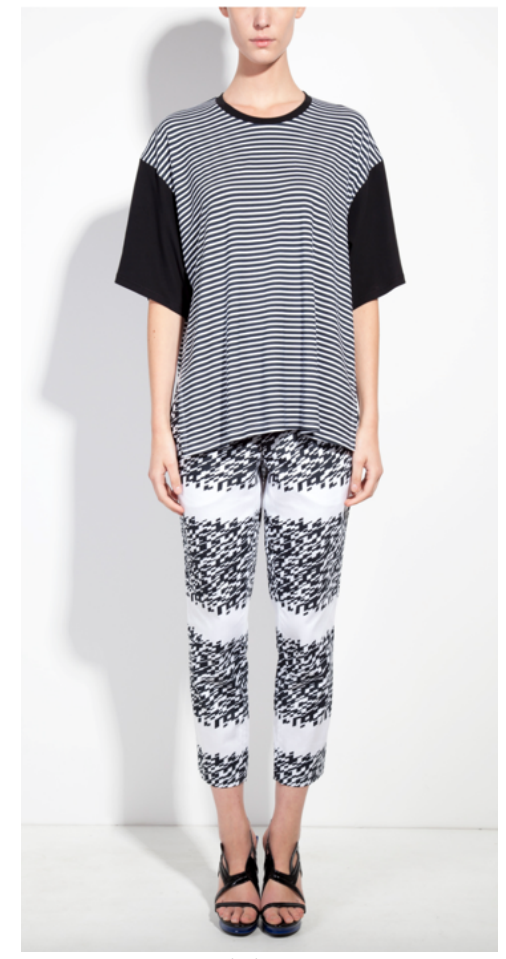

Exhibit 12:

Merchandise as retailed on the HonestBy website.

\section{Material information}

Product code: BPS025F2232P01U Product description: Printed jersey t-shirt with side slits and contrast sleeves

\section{FABRICS}

Main fabric: single jersey viscose

Composition: $93 \%$ viscose $7 \%$ elastane

Weight: $180 \mathrm{gr} / \mathrm{m}$

Yarn or piece dyed: piece dyed

Origin of raw material: More information was given to Honest by but the supplier did not wish to make that information public.

Manufacturer: More information was given to Honest by but the supplier did not wish to make that information

public.

Print information: The digital printing method used allows for accurate and optimal printing results combined with low ink cunsumption. The waste is minimal and there are fewer variations in finished print quality.

Printer/Supplier: Textilfab, Teningen, Germany -

www.textilfab.de (supplier was GOTS certified at time of purchase, july 2012)

Sleeve \& neck fabric: organic cotton jersey

Composition: $100 \%$ organic cotton

Weight: $120 \mathrm{gr} / \mathrm{m}$

Yarn or piece dyed: piece dyed

Certificate: GOTS

Origin of raw material: Izmir, Turkey

Location spinner: Izmir, Trikey

Location weave: Izmir, Turkey

Location Dyer/Finisher: Torbali, Izmir, Turke

Supplier: Alternativ Natur Produkte, Munich, Germany -

www.alternativnaturprodukte.de

\section{SEWING THREAD}

Composition: $100 \%$ organic cotton

Certificate: GOTS

Origin of raw material: Egypt

Manufacturer: Forbitex, Soest, the Netherlands -

www.forbitex.nl

Supplier: Forbitex, Soest, the Netherlands -

www.forbitex.nl

BRAND LABEL**

Composition: $100 \%$ polyester

Manufacturer: EE Labels, Heeze, the Netherlands -

www.eelabels.com

\section{SIZE LABEL**}

Composition: $100 \%$ polyester

Origin of raw material: China

Production plant location: Chin

Supplier: Labels and things, Kontich, Belgium -

www.labels-things.com

CARE LABEL + MADE IN LABEL

Composition: $100 \%$ cotton

Origin of raw material: More information was given to Honest by but the supplier did not wish to make that information public.

Manufacturer: Van Campenhoudt, Schaarbeek, Belgium Supplier: Van Campenhoudt, Schaarbeek, Belgium
SECURITY SEAL*

Composition: $100 \%$ polystyrene

Certificate: ISO 18001, certified manufacturer

Manufacturer: UNISTO, Italy - www.unisto.it

Supplier: UNISTO, Italy - www. unisto.it

HANG TAG

Composition: $100 \%$ recycled paper

Origin of raw material: Europe, mainly Germany

Manufacturer: Schollershammer, Düren, Germany -

www.schoellershammer.de

Supplier: IGEPA Belux, Aalter, Belgium - www.igepa.be Printer: EcoDrukkerij, Beernem, Belgium -

www.ecodrukkerij.be

\section{COTTON THREAD}

Composition: $100 \%$ cotton

Origin of raw material: More information was given to

Honest by but the supplier did not wish to make that information public.

ocation Manufacturer: Belgium. More information was given to Honest by but the supplier did not wish to make that information public.

Supplier: EE Labels, Heeze, the Netherlands www.eelabels.com

\section{SAFETY PIN}

Composition: 100\% nickel-free metal

Manufacturer: Rayher Hobby, Germany. Product was

made in the Czech Republic - www.rayher-hobby.de

Supplier: AVA papierwaren, Antwerp, Belgium -

www.ava.be

"For optimal decomposition: please remove all polyester garment labels before disposal. These are not biodegradable.

Exhibit 13: A sample of product information transparency.

Exhibits 14, 15 and 16 can be found in the Appendices. 


\subsubsection{Health and food labeling practices as potential reference model}

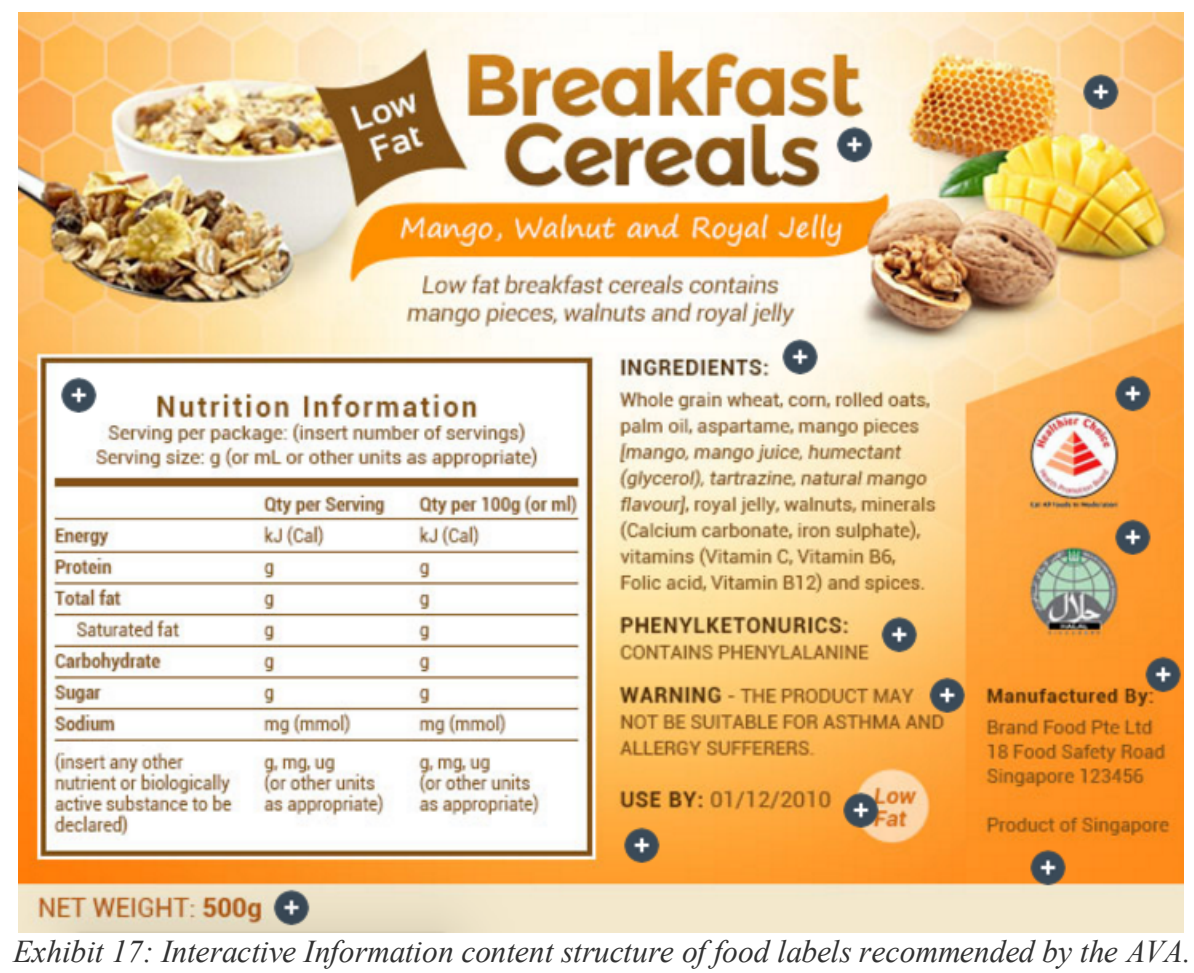

The AVA takes product labelling seriously, by providing interactive, detailed information on its website, that educates both the industry and the community regarding responsible product labelling in the market (Exhibit 17).

Because fashion product labelling remains highly unstructured in content information, there is potential that references could be made in the relatively more well-established food labelling system. In this instance, we make reference to the food labelling regulation set up by the Agri-Food and Veterinary Authority of Singapore (AVA, 2010): "It is an offence to sell prepacked foods without proper labelling or to make false or misleading claims for food products. The penalties for non-compliance are stated under Section 49 of the Sale of Food Act and regulation 261 of the Food Regulations; relevant sections are quoted as such: "Any person who is guilty of an offence under this Act for which no penalty is expressly provided shall be liable on conviction to a fine not exceeding $\$ 5,000$ and, in the case of a second or subsequent conviction, to a fine not exceeding $\$ 10,000$ or to imprisonment for a term not 
exceeding 3 months or to both" (AVA, 2010). No such law or regulation exists at the moment for fashion product labelling.

According to the AVA regulations (Exhibit 18), the stipulated process for responsible labelling starts with the classification of products: (1) a part of daily diet; (2) ingested as supplement to a diet; and (3) ingested as medicines. Depending on the food product category, labellers would need to adhere to either AVA or HSA.

\section{Step 1: Classification of products}

The following classification tree provides guidance for the classification of products whose presentation, ingredients or function fall into the food-health product interface.

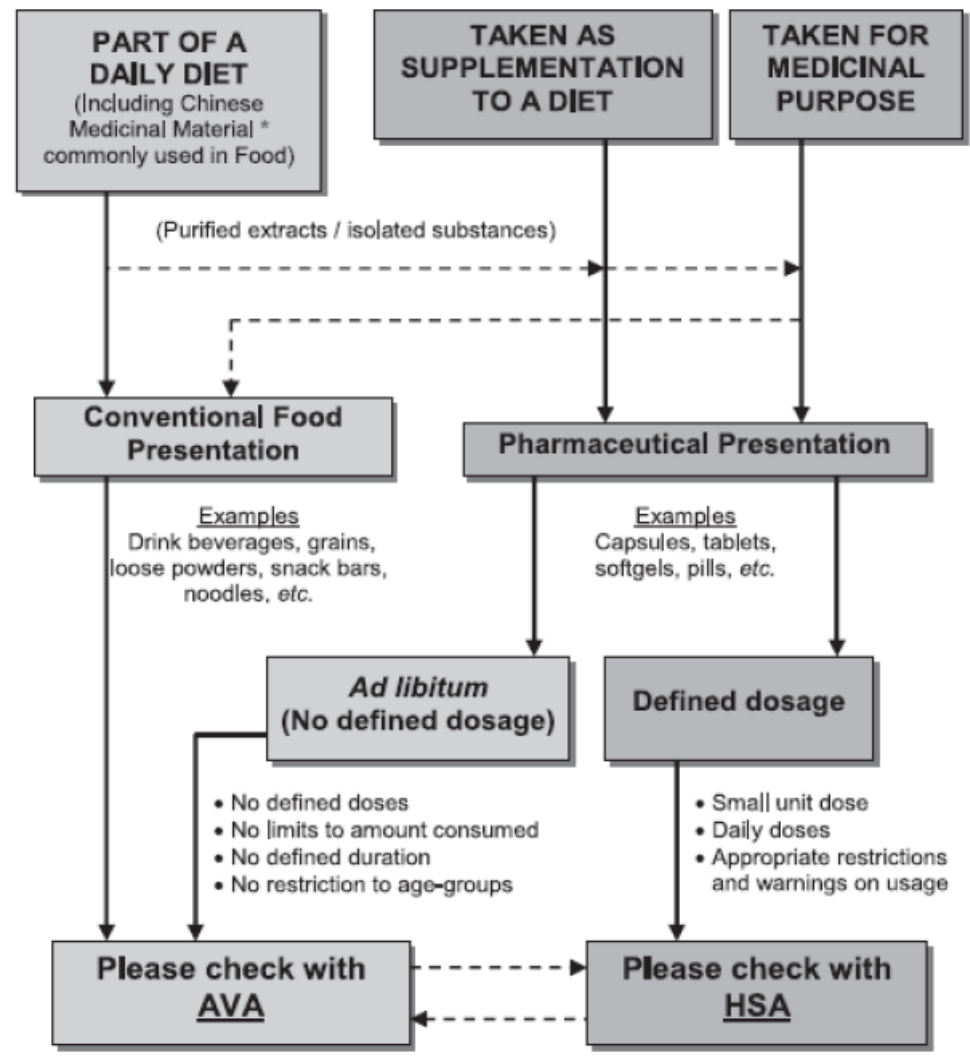

Exhibit 18: Type of product classification.

As a second step (Exhibit 19), labellers would have to follow the laid-out general labelling requirements, with the following items such as (1) product name or description of food; (2) ingredients list; (3) allergen declaration; (4) declaration of net content in quantity or drained weight; (5) country of origin, name and address of local agent for imported food; (8) 
name and address of the domestic vendor. These requirements also have the English language and height specifications for content.

\section{Step 2: General labelling requirements}

For those items marked "No" in this section, please revise your label accordingly.

\begin{tabular}{|c|c|c|c|}
\hline No. & General Labelling Requirements & Yes & No \\
\hline 1. & $\begin{array}{l}\text { Product Name: An acceptable common name or } \\
\text { description which is sufficient to indicate the true } \\
\text { nature of the product. }\end{array}$ & & \\
\hline 2(i). & $\begin{array}{l}\text { Ingredients List: All ingredients and additives } \\
\text { used in the product are listed in descending order } \\
\text { by proportion of weight. }\end{array}$ & & \\
\hline 2(ii). & $\begin{array}{l}\text { Allergen Labelling: This includes the declaration } \\
\text { of foods and ingredients (including components } \\
\text { of compound ingredients) that are known to } \\
\text { cause hypersensitivity. }\end{array}$ & & \\
\hline 3(i). & $\begin{array}{l}\text { Quantity: The net quantity of the food in the } \\
\text { package expressed in terms of } \\
\text { (i) volumetric measure (for liquid food } \\
\text { products) } \\
\text { (ii) net weight (for solid food products) or } \\
\text { (iii) either volumetric or weight measure for } \\
\text { semi-solid or viscous products. }\end{array}$ & & \\
\hline 3(ii) & $\begin{array}{l}\text { Drained weight: This is the weight of the food } \\
\text { minus the liquid medium; and applies only to } \\
\text { foods packed in liquid medium. }\end{array}$ & & \\
\hline 4. & $\begin{array}{l}\text { Imported Food: Name of the country of origin of } \\
\text { the product. Name and address of your company } \\
\text { as the importer, distributor or agent in Singapore. }\end{array}$ & & \\
\hline 5. & $\begin{array}{l}\text { Locally manufactured food: Name and address } \\
\text { of the manufacturer, packer or local vendor. }\end{array}$ & & \\
\hline 6. & Are items (1) to (5) printed in English? & & \\
\hline 7. & $\begin{array}{l}\text { Are items (1) to (3) printed in letters not less } \\
\text { than } 1.5 \mathrm{~mm} \text { in height? }\end{array}$ & & \\
\hline
\end{tabular}

Exhibit 19:

A detailed checklist that aids businesses and labelers in responsible product labelling.

Steps 3 and 4 (Exhibit 20) outline additional labelling requirements, including special health claims that need to be evidenced by third-party certifications, and endorsed by regulators AVA or HPB. According to Regulation 261 of the AVA Food Regulations (2010), "Any person who contravenes or fails to comply with any of the provisions of these Regulations shall be guilty of an offence and shall be liable on conviction to a fine not exceeding $\$ 1,000$ and in the case of a second or subsequent conviction to a fine not exceeding $\$ 2,000 . "$ 
Step 3: Use of claims on food labels and advertisements

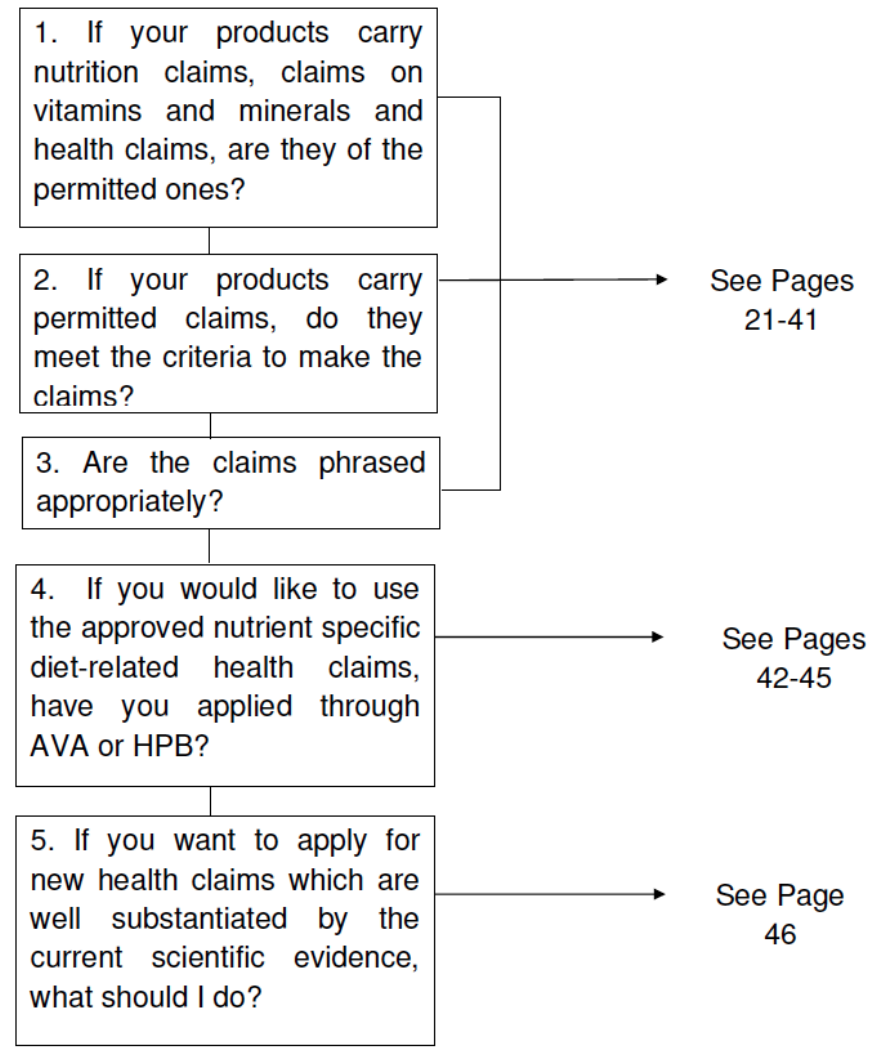

Step 4: Additional labelling requirements

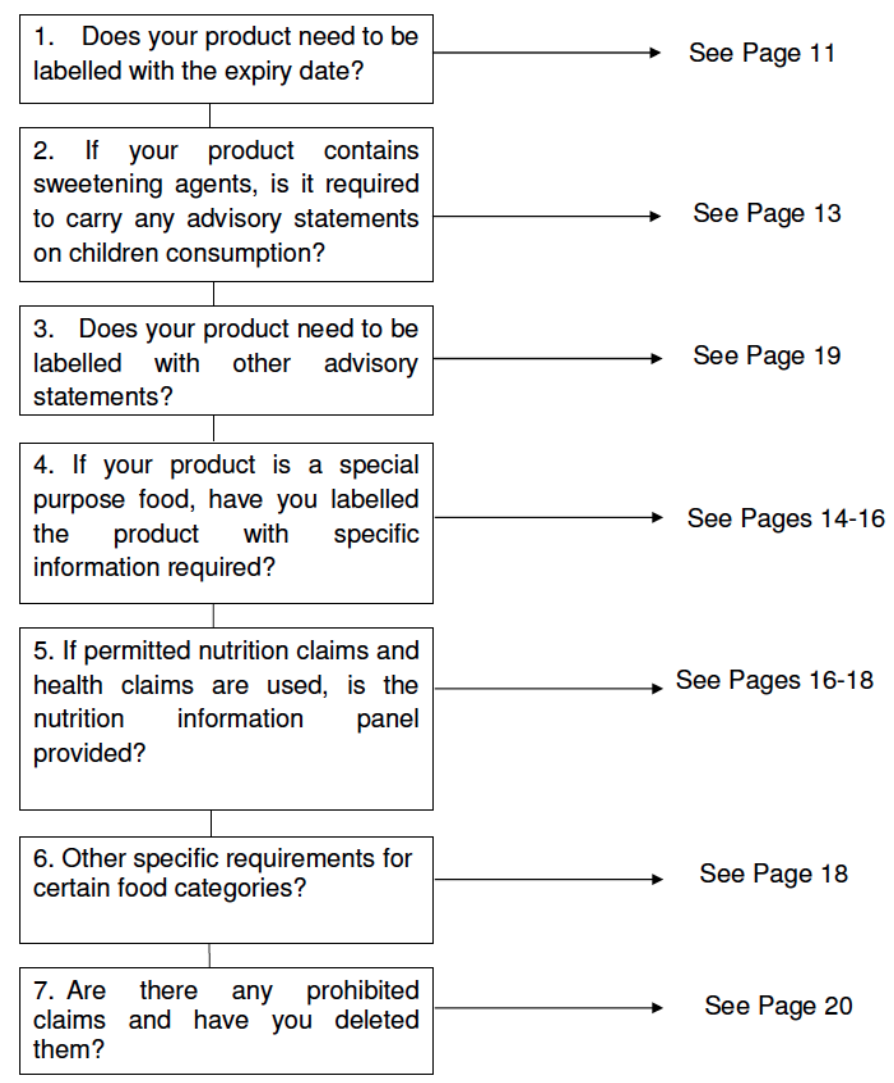

Exhibit 20: Additional labelling requirements that ensures responsible, accurate product information. 


\subsection{Limitations}

The key limiting factor in this research has been the apparent small size of the sample in this content analysis. Because of this limitation, the t-test and cross-tab tests have both yielded insignificant results. Also, the nature of the subject of fashion products in this study are by nature, diverse. This adds on to the need for a much larger sample size to be studied, taking into account adequate representation from brands of various geographical and price markets, cultures, business models and product class offering.

Moreover, many of the research questions involve the analysis of very specific premises, such as green labels, fair trade labels, brand origins and design origins. These further limited the already-small total sample size of 60 for this study. However, results drawn from this study could contribute to further research, especially in the cross-analysis of product labelling structures and the difference in information strategies used across various consumer markets.

\subsection{Conclusion}

As evidenced in this paper, strategies that fashion brands use to drive commerce and increased levels of consumption are numerous: brand name; country-effect references; ethical production stories; the creation of brand provenance and green cues are among the most common tools observed in the market today. It has been established that product labelling standards are led by consumer demands and consumption patterns. As consumer tastes evolve in relation to socioeconomic and cultural environments, the methods that markets use to attract customers would also change.

Even though prevailing trends in literature indicate the $\mathrm{COO}$ as a critical factor in studies of this category, the increasingly "multi-locational nature" (Samiee, 2011, pp. 474 cited in $\mathrm{Wu}$ et al., 2016, pp. 203) of the production of modern goods would overrate the significance of a single country-effect of the labelled COO. This was exhibited in the 
research paper by taking into account other country-effects in the relevant equation, such as the COE and COD. However, due to the aforementioned limitation in the small sample size of this study, we were unable to scientifically conclude relationships within this countyeffects strategy. Nevertheless, there is value in elevating this study in terms of scale and market diversity.

It is hence critical to embark on future relevant research, to investigate the changing dynamics between information types and how they interact with one another on the product label when communicating to the customer. This would need to be done in consideration of external factors such as geography, local market cultures, product and brand classes, compared against other industry standards in product labelling and evolution in time. 


\section{References}

Adams, T. (2015, June 14). Op-Ed | The Brand Power of 'Made in'. Retrieved July 10, 2017, from https://www.businessoffashion.com/community/voices/discussions/does-madein-matter/harnessing-the-power-of-made-in-labelling

Agri-Food \& Veterinary Authority, Singapore. (2010). A Guide to Food Labelling and Advertisements (pp. 1-56). Singapore, SINGAPORE: Agri-Food \& Veterinary Authority. Retrieved January 30, 2017, from http://www.ava.gov.sg/docs/defaultsource/tools-and-resources/resources-for-

businesses/aguidetofoodlabellingandadvertisementsversionjuly2

Aspers, P. (2008). Labelling fashion markets. International Journal of Consumer Studies, 32(6), 633-638. doi:10.1111/j.1470-6431.2008.00724.x

Belgum, D. (2014, July 17). Controversy Over the 'Made in USA' Label. Retrieved February 17, 2017, from https://www.apparelnews.net/news/2014/jul/17/controversyover-made-l-label/

Bennett, S. (2011, January 24). Country of origin labelling. Retrieved July 14, 2017, from http://www.fashionlaw.co.uk/site/fashion_focus/country_of_origin_labelling.html

Bray, J., Johns, N., \& Kilburn, D. (2010). An Exploratory Study into the Factors Impeding Ethical Consumption. Journal of Business Ethics, 98(4), 597-608.

doi:10.1007/s10551-010-0640-9

Business Review USA (2013, March 19). Retailers Settle with FTC Over Fur Mislabeling. Retrieved February 18, 2017, from http://www.businessreviewusa.com/finance/4109/Retailers-Settle-with-FTC-OverFur-Mislabeling

Cadwalladr, C. (2012, July 16). The hypocrisy of Burberry's 'Made in Britain' appeal | Carole Cadwalladr. Retrieved February 18, 2017, from https://www.theguardian.com/commentisfree/2012/jul/16/burberry-china-britishcarole-cadwalladr

Chesters, L. (2014, February 01). Ta-ta tartan, bonjour haute couture: Scotland's textile trade reinvents itself as a purveyor of luxury goods. Retrieved April 14, 2017, from http://www.independent.co.uk/news/business/news/ta-ta-tartan-bonjour-hautecouture-scotlands-textile-trade-reinvents-itself-as-a-purveyor-of-luxury-9101653.html

Cowe, R. and S. Williams: 2000, 'Who are the Ethical Consumers?', Ethical Consumerism Report, Cooperative Bank. http://www.cooperativebank.co.uk/servlet/Satellite?c=Pageandcid=1139903089615an dpagename $=$ CoopBank $\% 2$ FPage $\% 2$ FtplPageStandard.

Ethical Fashion Forum (2011). Standards and Labelling. Ethical Fashion Forum. Retrieved from http://www.ethicalfashionforum.com/the-issues/standards-labelling 
Evan, D. J. and Maguire, J. L. (2015, December). FTC assesses \$1.3 million in penalties for mislabeling rayon textiles as bamboo. GDLSK. Retrieved from http://www.gdlsk.com/firm-news/371-ftc-assesses-13-million-in-penalties-formislabeling-rayon-textiles-as-bamboo.html

Federal Trade Commission (2015). Nordstrom, Bed Bath \& Beyond, Backcountry.com, and J.C. Penney to Pay Penalties Totaling \$1.3 Million for Falsely Labeling Rayon Textiles as Made of "Bamboo". Retrieved February 17, 2017, from https://www.ftc.gov/news-events/press-releases/2015/12/nordstrom-bed-bath-beyondbackcountrycom-jc-penney-pay-penalties

Hadjimichael, M., \& Hegland, T. J. (2016). Really sustainable? Inherent risks of eco-labeling in fisheries. Fisheries Research, 174, 129-135. Retrieved March 01, 2017.

Han, T., \& Chung, J. (2014). Korean Consumers' Motivations and Perceived Risks Toward the Purchase of Organic Cotton Apparel. Clothing and Textiles Research Journal, 32(4), 235-250. doi:10.1177/0887302x14538116

Hi-Tech Printing and Labelling Inc. (2015, May 29). Customers Prefer Products with a Personal Touch. Retrieved January 14, 2017, from http://www.prnewswire.com/newsreleases/customers-prefer-products-with-a-personal-touch-300091109.html

Joergens, C. (2006). Ethical fashion: myth or future trend? Journal of Fashion Marketing and Management: An International Journal,10, 360-371. Retrieved January 14, 2017.

Jones, A. R., \& Williams, G. (2012). Perceptions of fair trade labelling and certification: Three case studies. Journal of Fashion Marketing and Management: An International Journal Jnl of Fashion Mrkting and Mgt, 16(2), 246-265. doi:10.1108/13612021211222851

Lee, N., Choi, Y. J., Youn, C., \& Lee, Y. (2012). Does Green Fashion Retailing Make Consumers More Eco-friendly?: The Influence of Green Fashion Products and Campaigns on Green Consciousness and Behavior. Clothing and Textiles Research Journal, 30(1), 67-82. doi:10.1177/0887302x12446065

Ma, Y. J., Littrell, M. A., \& Niehm, L. (2012). Young female consumers' intentions toward fair trade consumption. Intl J of Retail \& Distrib Mgt International Journal of Retail \& Distribution Management, 40(1), 41-63. doi:10.1108/09590551211193595

Mellery-Pratt, R. (2015, June 14). Does 'Made in' matter? Retrieved February 14, 2017, from https://www.businessoffashion.com/community/voices/discussions/does-made-inmatter

Melser, D., \& Robertson, P. E. (2005). Eco-labelling and the Trade-Environment Debate. The World Economy, 28(1), 49-62. doi:10.1111/j.1467-9701.2005.00674.x

Minney, S. (2015, June 18). Op-Ed | Fair Trade Goes Beyond 'Made in'. Retrieved July 14, 2017, from https://www.businessoffashion.com/community/voices/discussions/doesmade-in-matter/op-ed-fair-trade-goes-beyond-made-in 
Nazzari, J. (2015, July 08). Op-Ed | Provenance Matters. Where Can I Get Some? Retrieved February 6, 2017, from https://www.businessoffashion.com/community/voices/discussions/does-made-inmatter/op-ed-provenance-matters-where-can-i-get-some

Oh, K., \& Abraham, L. (2015). Effect of knowledge on decision making in the context of organic cotton clothing. International Journal of Consumer Studies, 40(1), 66-74. doi:10.1111/ijcs.12214

Papadoupoulos, N., \& Heslop, L. (2000). Countries as brands: Canadian products abroad. Ivey Business Journal,30-36. Retrieved February 10, 2017.

Rashid, M. S. (2016). Weakening the Effect of Unfavorable Country of Origin: A Processand Parameter-Associated Theoretical Framework. Journal of Global Marketing,30, 87-98. Retrieved May 18, 2017.

Ritch, E., \& Schroder, M. (2012). Accessing and affording sustainability: the experience of fashion consumption within young families. International Journal of Consumer Studies, 36, 203-210. Retrieved January 05, 2017.

Ruppert-Stroescu, M., Lehew, M. L., Connell, K. Y., \& Armstrong, C. M. (2015). Creativity and Sustainable Fashion Apparel Consumption: The Fashion Detox. Clothing and Textiles Research Journal, 33(3), 167-182. doi:10.1177/0887302x15579990

Solca, L. (2015, June 14). The 'Made In' Dilemma: To Label, or Not to Label. Retrieved February 14, 2017, from https://www.businessoffashion.com/community/voices/discussions/does-made-inmatter/the-made-in-dilemma-to-label-or-not-to-label

Tang, E., Fryxell, G. E., \& Chow, C. S. (2004). Visual and Verbal Communication in the Design of Eco-Label for Green Consumer Products. Journal of International Consumer Marketing,16(4), 85-105. doi:10.1300/j046v16n04_05

Wu, L., Ju, I., \& Dodoo, N. A. (2016). Understanding the Impact of Matchup between Country-of-Origin Facets and Country Stereotypes on Advertising Effectiveness. Journal of Global Marketing, 29(4), 203-217. doi:10.1080/08911762.2016.1185561 


\section{Appendices}

\section{Manufacturing details}

Product code: BPS025F2232P01U

Product description: Printed jersey t-shirt with side slits and contrast sleeves

PATTERN

Company: Trois Quarts

Number of fittings: 3

THIS GARMENT IS 100\% MADE IN EUROPE FOR HONEST BY.

\section{Price calculation}

Product code: BPS025F2232P01U

Product description: Printed jersey t-shirt with side slits and contrast sleeves

\section{FABRIC}

Main fabric: single jersey viscose

Amount used: 0,80 meter

Price / Meter: The information was given to Honest by

but the supplier did not wish to make that information

public.

Fabric: organic cotton jersey

Price / Meter: 5,98 Euro/m

Amount used: 0,40 meter

Total: 2,392 Euro

SEWING THREAD

Sewing thread: $100 \%$ organic cotton GOTS certified

Price / Cone: 9,50 Euro

Estimated cost: 0,5 Euro

BRAND LABEL

Brand label small: $100 \%$ polyester

Price / Piece : 0,5864 Euro

Amount used: 1 piece

Total: 0,5864 Euro

\section{SIZE LABEL}

Size label: $100 \%$ polyester

Price / Piece : 0,035 Euro

Amount used: 1 piece

Total: 0,035 Euro

CARE LABEL + MADE IN LABELS

Care labels + made in labels: $100 \%$ cotton

Price / Piece : 0,74 Euro (average for both together)

Amount used: 1 piece

Total: 0,74 Euro
SECURITY SEAL

Security seal : $100 \%$ polystyrene

Price / Piece: 0,2 Euro

Amount used: 1 piece

Total: 0,2 Euro

HANG TAGS

Hang tags: $100 \%$ FSC recycled

Price / Piece: 0,29 Euro

Amount used: 1 piece

Total: 0,29 Euro

COTTON THREAD

Cotton thread: $100 \%$ cotton

Price / Piece: 0,016 Euro/m

Amount used: 0,3 meter

Total: 0,0048 Euro

\section{SAFETY PINS}

Safety pin: $100 \%$ polystyrene

Price / Piece: 0,03 Euro

Amount used: 1 piece

Total: 0,03 Euro

TOTAL COST MATERIALS: 12.85 Euro

MANUFACTURING COST

Garment manufacturing: 15,00 Euro
TOTAL COST: 27,85 EURO

WHOLESALE MARK UP: X 2,0

= 55,7 Euro

The wholesale mark up covers a part of the Bruno

Pieters studio costs such as staff, research, design,

utility costs, transportation and office supplies.

RETAIL MARK UP: $\times 2,0$

$=111,4$ Euro

This retail mark up covers Honest by's costs such as

staff, purchasing of new collections, operational costs,

utility costs, rent, insurance, communications,

transportation, intellectual property rights, professional

association costs, office supplies, maintenance costs,

legal and accounting costs, and marketing.

HONEST BY RETAIL PRICE (excl. VAT): 111,4 EURO This price is applicable to non-EU customers. Import duty taxes apply.

HONEST BY RETAIL PRICE (incl. VAT): 134,79 EURO This price is applicable to EU customers only. VAT is included in this price.

NOTE: Due to a discount on the above price from ou Sale Periods the final garment price appears different.

Note: All prices are calculated per 1 item

Exhibit 14: A sample of product information transparency. 
INFORMATION ABOUT OUR FILTERS:

ORGANIC

Our organic filter means that the main fabric or the raw material content of the main fabric of a Honest by garment is certified organic. The filter does not apply to the final product. Neither honest by, nor the production facilities Honest by works with, are certified organic at the moment.

\title{
VEGAN
}

Veganism is the practice of abstaining from the use of animal products.

Our Vegan filter means that these Honest by products do not contain leather, wool, silk, horn, shell or any other substance produced from animals.

\section{SKIN FRIENDLY}

Our skin friendly filter means that the main fabric used to make the garment does not endanger the health of your skin. Skin friendly certificates are Oeko-tex, Ivn, Gots, Joca and Sacl. View general certificate information for more details. This filter does not apply to the final product.

\section{RECYCLED}

Recycled fabrics and yarns are made of post consumer waste which is purchased in bulk. The waste is sorted by color and respun into yarn. Depending on the end product, it will be used for knitting or weaving fabrics. The biggest advantage of sorting by color is that the yarn does not have to be dyed, hence the production of recycled wool yarn saves on energy and water use.

\author{
EUROPEAN \\ The European filter means the garment was 100\% manufactured in Europe.
}

\section{ANIMAL WELFARE}

Honest by strictly works with suppliers that have a GOTS certificate (view GOTS) or a 100\% British Wool Certificate. The National Sheep Association in the UK which safeguards the interest of sheep and farmers within the UK has confirmed that sheep in the UK are not genetically modified; their genetic material has not been altered using genetic engineering techniques. For centuries, though, farmers have selected the best rams and ewes to bread in order to have a higher production quality. All farmers must comply to British and European legislation which has formulated laws regarding good husbandry, transport and animal welfare amongst other things. Dehorning and mulesing are not practiced in the UK. Tail docking happens everywhere in the UK. It is a recognized practice monitored by the government. Some farmers we have interviewed considered this a controversial practice, whilst others believe this practice benefits the welfare of the animals. In their opinion tail docking facilitates the treatment sheep undergo when infected with flystrike. Some sheep breeds, such as Shetland, have such short tails that tail docking is unnecessary. Hebrideans on the other hand are Northern Short Tail sheep, their tail is still quite long but native breeds are more resistant to fly strike if they stay in their natural environment; thus they often also do not get tail docked. Ear notching was an old tradition to recognize one sheep from one farm to another and is no longer practiced in the UK. Nowadays legal requirements force ear tags in both ears of a sheep.

Please do not hesitate to contact Honest by in case you would have any questions or remarks about our products. contact@honestby.com

\section{Exhibit 15: A sample of product information transparency.}

\section{GENERAL INFORMATION ABOUT CERTIFICATES:}

\section{GOTS}

The Global Organic Textile Standard (GOTS) is the worldwide leading textile processing standard for organic fibers, including ecological and social criteria. The aim of the standard is to define world-wide recognized requirements that ensure organic status of textiles, from harvesting of the raw materials, through environmentally and socially responsible manufacturing up to labeling in order to provide a credible assurance to the end consumer. The EU organic regulation is the legal basis for the control of organic farming and food processing in Europe. The Global Organic Textile Standard has the EU organic regulation as its baseline: it starts where the European Legislation ends. This legislation contains (amongst other standards): standards for crop production, standards for livestock husbandry: e.g.. duration of transport of livestock shall be minimized; any suffering, including mutilation, shall be kept to a minimum during the entire life of the animal.

Organic is a 'whole system' approach to farming and food production. It recognizes the close interrelationships between all parts of the production system from the soil to the consumer. Agricultural principles are: To produce food of high quality in sufficient quantity. To work within natural systems and cycles throughout all levels from the soil to plants and animals. To maintain the long term fertility and biological activity of soils. To treat livestock ethically, meeting their physiological and behavioral needs. To respect regional, environmental, climatic and geographic differences and (appropriate) practices that have evolved in response to them

Organic farming: Organic farming means livestock has to be managed with special care for their welfare and health, the animals' behavioral needs should be satisfied. It goes beyond merely avoiding cruelty. One should: aim to prevent disease and injury, increase the ability of stock to resist infection, parasitic attack and metabolic disorders, and increase their ability to overcome injury by rapid healing. Animals should enjoy the 'five freedoms' - freedom from: malnutrition, physical discomfort and extremes of temperature, injury and disease, fear and distress, unnecessary restrictions of behavior.

Environmental criteria: At all stages through the processing organic fibre products must be separated from conventional fiber products and must to be clearly identified. All chemical inputs (e.g. dyes, auxiliaries and process chemicals) must be evaluated and meeting basic requirements on toxicity and biodegradability/eliminability. Prohibition of critical inputs such as toxic heavy metals, formaldehyde, aromatic solvents, functional nano particles, genetically modified organisms (GMO) and their enzymes. The use of synthetic sizing agents is restricted; knitting and weaving oils must not contain heavy metals. Bleaches must be based on oxygen (no chlorine bleaching). Azo dyes that release carcinogenic amine compounds are prohibited. Discharge printing methods using aromatic solvents and plastisol printing methods using phthalates and PVC are prohibited. Restrictions for accessories (e.g. no PVC, nickel or chrome permitted, any polyester must be post-consumer recycled from 2014 onwards). All operators must have an environmental policy including target goals and procedures to minimize waste and discharges. Wet processing units must keep full records of the use of chemicals, energy, water consumption and waste water treatment, including the disposal of sludge. The waste water from all wet processing units must be treated in a functional waste water treatment plant. Packaging material must not contain PVC.

For more information on this standard please visit the website: www.global-standard.org

NOTE: The standard does not apply to the final product. Neither honest by, nor the production facilities Honest by works with are certified at the moment.

\section{IVN}

The Internationale Verband der Naturtextilwirtschaft is a founder member of Global Standard GmbH, the managing body of the Gobal Organic Textile Standard (GOTS). Since 2002 they have worked with SACL (UK), OTA (USA) and JOCA (Japan) to develop the unified global organic textile standards, which were launched in 2006

IVN offers besides GOTS as its basic standard one further standard for certification that complies with GOTS but contains some additional requirements.(regarding composition, dyes and auxiliary agents, mercerization, etc...). This is the Naturtextil Certified Best label.

For more information on the standard please visit the website: www.naturtextil.com

NOTE: The standard does not apply to the final product. Neither honest by, nor the production facilities Honest by works with are certified at the moment.

Exhibit 16: A sample of product information transparency. 